\title{
Inosine Substitutions in RNA Activate Latent G-Quadruplexes
}

\section{Journal Article}

Author(s):

Hagen, Timo (D); Laski, Artur; Brümmer, Anneke; Pruska, Adam (1); Schlösser, Verena; Cléry, Antoine; Allain, Frédéric H.-T.; Zenobi, Renato (D); Bergmann, Sven; Hall, Jonathan

Publication date:

2021

Permanent link:

https://doi.org/10.3929/ethz-b-000508930

Rights / license:

Creative Commons Attribution-NonCommercial-NoDerivatives 4.0 International

Originally published in:

Journal of the American Chemical Society 143(37), https://doi.org/10.1021/jacs.1c05214 


\title{
Inosine Substitutions in RNA Activate Latent G-Quadruplexes
}

\author{
Timo Hagen, Artur Laski, Anneke Brümmer, Adam Pruška, Verena Schlösser, Antoine Cléry, \\ Frédéric H.-T. Allain, Renato Zenobi, Sven Bergmann, and Jonathan Hall*
}

Cite This: J. Am. Chem. Soc. 2021, 143, 15120-15130

Read Online

ACCESS

W Metrics \& More

Article Recommendations

Supporting Information

ABSTRACT: It is well-accepted that gene expression is heavily influenced by RNA structure. For instance, stem-loops and Gquadruplexes (rG4s) are dynamic motifs in mRNAs that influence gene expression. Adenosine-to-inosine (A-to-I) editing is a common chemical modification of RNA which introduces a nucleobase that is iso-structural with guanine, thereby changing RNA base-pairing properties. Here, we provide biophysical, chemical, and biological evidence that A-to-I exchange can activate latent $\mathrm{rG} 4 \mathrm{~s}$ by filling incomplete G-quartets with inosine. We demonstrate the formation of inosine-containing rG4s (GIquadruplexes) in vitro and verify their activity in cells. GIquadruplexes adopt parallel topologies, stabilized by potassium

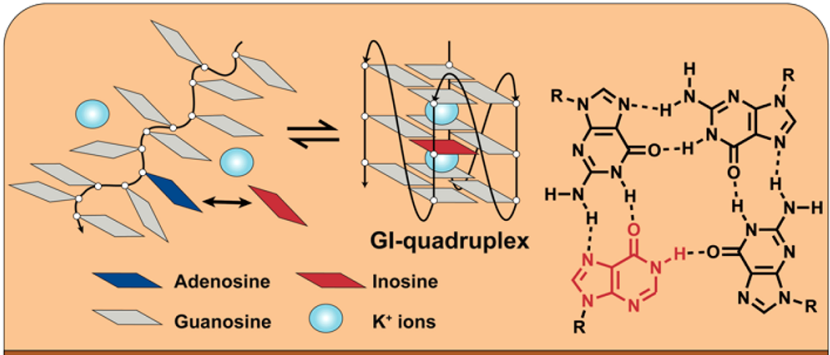

INOSINE QUADRUPLEXES IN RNA ions. They exhibit moderately reduced thermal stability compared to conventional G-quadruplexes. To study inosine-induced structural changes in a naturally occurring RNA, we use a synthetic approach that enables site-specific inosine incorporation in long RNAs. In summary, RNA GI-quadruplexes are a previously unrecognized structural motif that may contribute to the regulation of gene expression in vivo.

\section{INTRODUCTION}

G-quadruplexes are widespread in the transcriptome ${ }^{1,2}$ where they influence transcription termination, polyadenylation, splicing, and translation and serve as binding sites for RNAbinding proteins. ${ }^{3}$ They consist of stacked G-quartets, formed from sequences comprising four tracts of guanosine repeats. ${ }^{4,5}$ A G-quadruplex is stabilized by eight hydrogen bonds ( $\mathrm{H}$ bonds) between the Watson-Crick/Hoogsten faces of guanines, by $\pi-\pi$ stacking between the planar faces of the G-quartets and by the coordination of potassium ions with guanine oxygens in the central cavities ${ }^{6}$ (Figure 1a). A canonical three-stacked rG4 typically has short-loops and a stable compact structure. ${ }^{7}$ However, noncanonical rG4s with highly unusual structures are increasingly described. ${ }^{8-10}$ For example, transcriptome-wide searches have identified numerous putative rG4s, comprising G2-tracts and long, structured loops. ${ }^{2}$ Moreover, it is likely that many unusual rG4s exist that cannot yet be predicted by current computational methods. ${ }^{8,9}$ These structures may exhibit reduced stabilities and, hence, lowered barriers for conformational exchanges that facilitate functional responses. $^{11}$

The adenosine-to-inosine (A-to-I) editing reaction of RNA is performed by dsRNA-specific adenosine deaminases (ADARs), which convert adenosine to inosine via hydrolytic deamination. $^{12,13}$ This causes changes in the base-pairing properties of the ribonucleotide relative to adenosine: As inosine lacks only the 2-amino group of guanosines, ribosomes and the splicing machinery read inosines in edited mRNAs as guanosines. Similarly, the introduction of inosine in microRNAs (miRNAs), or in miRNA-binding sites, can alter miRNA biogenesis and miRNA target recognition. ${ }^{14-16}$ The introduction of inosine may have regulatory effects by stabilizing or destabilizing RNA secondary structures. Several recent studies report context-dependent stabilizing effects of A-to-I exchange on RNA secondary structure. ${ }^{17-19}$ Alternatively, editing at A-U base pairs can destabilize hairpin structures, breaking the two $\mathrm{H}$-bonds in the Watson-Crick base-pair. ${ }^{20}$ Of note, editing levels of a particular adenosine can differ widely among different tissues/developmental stages with detected editing levels of $<1 \%$ up to almost $100 \% .^{21-23}$

Given the similarity of the $\mathrm{H}$-bonding register in inosine and guanosine, we reasoned that inosine might substitute for guanosine in RNA G-quartets. Namely, loss of one H-bond between the 2- $\mathrm{NH}_{2}$ group and the $\mathrm{N}^{7}$ of neighboring guanosines would not significantly destabilize a quadruplex (Figure 1a). Indeed, inosine-containing G-quartets have previously been leveraged to relax stable DNA G-quadruplexes for study. ${ }^{24}$ It followed that A-to-I exchange at specific positions might fill an incomplete RNA G-quartet and switch

Received: May 20, 2021

Published: September 14, 2021 
a

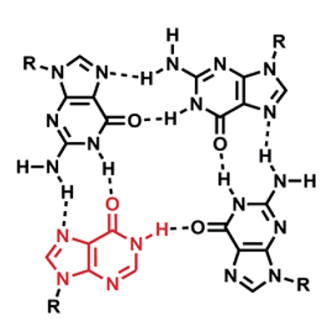

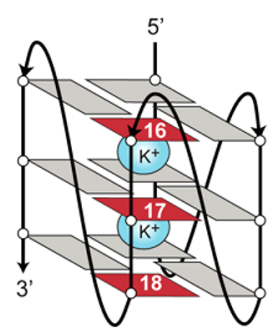
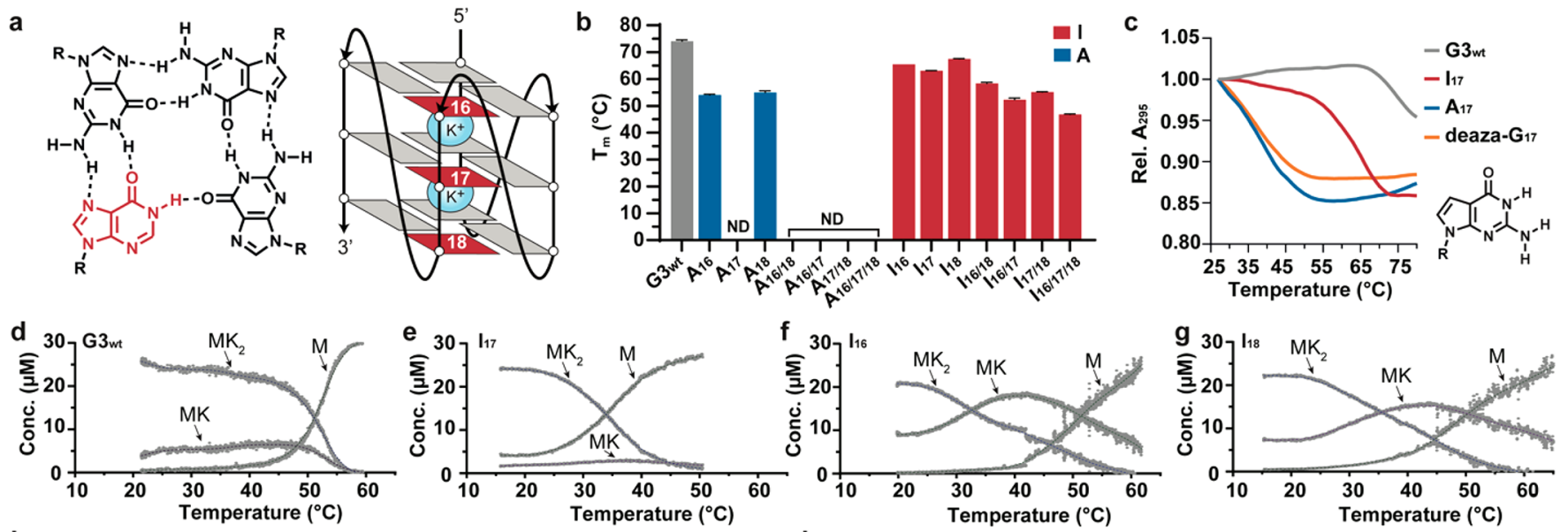

h
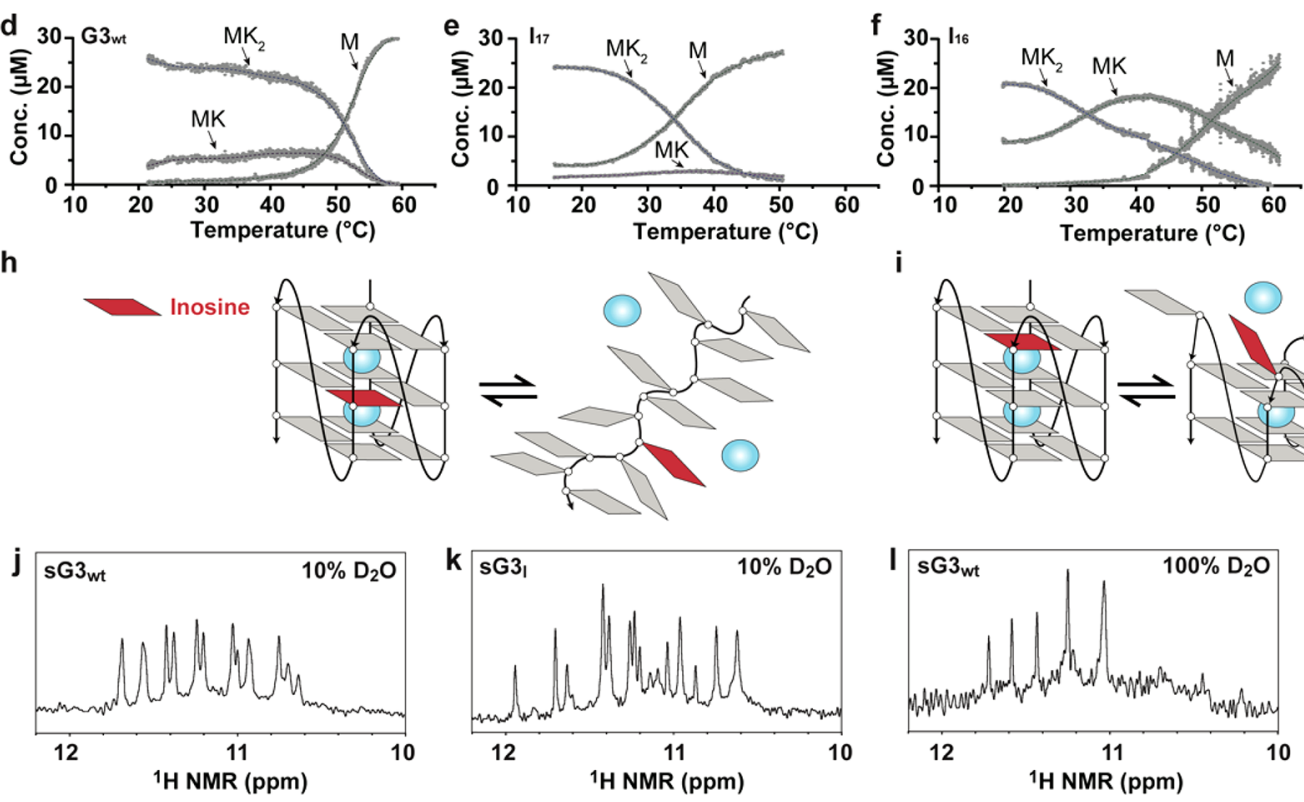

i
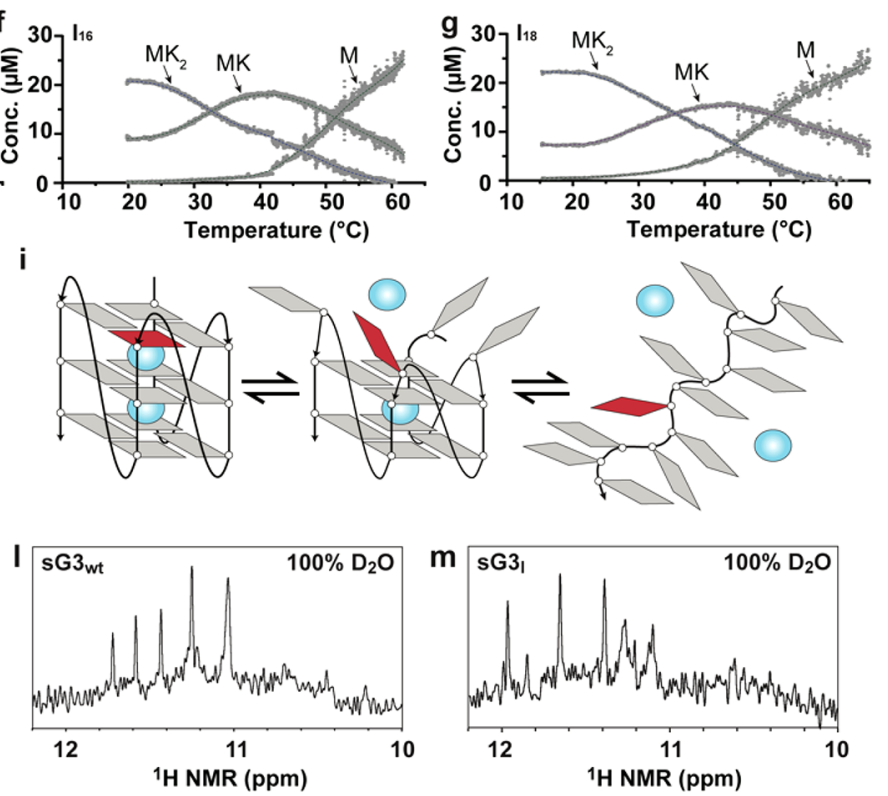

Figure 1. Biophysical characterization of GI-quadruplex formation in vitro. (a) Inosine lacks the 2-amino group, leading to the loss of one hydrogen bond with the $\mathrm{N}^{7}$ of the neighboring guanosine in a $\mathrm{G}_{3} \mathrm{I}$-quartet. Structure of a conventional RNA G3-quadruplex (rG4) model sequence (G3 ${ }_{\text {wt }}$; $5^{\prime}$ AAAAGGGCUGGGGCUG ${ }_{16} \mathrm{G}_{17} \mathrm{G}_{18} \mathrm{CGGGGA-3}^{\prime}$ ) with three quartets linked by loops with parallel orientation. Annotated in red (16-17-18) is G-tract where guanosines were substituted to inosines or adenosines. (b) Melting temperatures at $295 \mathrm{~nm}$ in $3 \mathrm{mM} \mathrm{KCl}$ for $\mathrm{G} 3_{\mathrm{wt}}$ (gray) and substitution variants: G-A (blue) and G-I (red). Data represent mean + SD from three consecutive scans. ND: not detected. (c) Melting curves at 3 $\mathrm{mM} \mathrm{KCl}$ for I, A, or 7-deaza G substitutions at position 17 normalized to the signal at $25^{\circ} \mathrm{C}$. Incorporation of 7 -deazaguanosine at position 17 abolishes quadruplex formation. ${ }^{29}$ Inset: Chemical structure of 7-deazaguanosine. (d-g) Thermal melting experiment monitored with mass spectrometry at $0.1 \mathrm{mM} \mathrm{KCl}$ for: (d) $\mathrm{G}_{\mathrm{wt}}$, (e) $\mathrm{I}_{17},(\mathrm{f}) \mathrm{I}_{16}$, and $(\mathrm{g}) \mathrm{I}_{18}$. The curves indicate quantified stoichiometries as a function of temperature after subtracting the nonspecific adduct contributions. (h, i) Suggested mode of quadruplex unfolding: (h) model for G3 ${ }_{w t}$ and $I_{17}$ and (i) model for $\mathrm{I}_{16}$ and $\mathrm{I}_{18} \cdot(\mathrm{j}-\mathrm{m}){ }^{1} \mathrm{H}$ NMR spectra of the imino region between 10 and $12 \mathrm{ppm}$ in the presence of $25 \mathrm{mM} \mathrm{KCl}$ corresponding to sG $3_{\text {wt }}$ in $(\mathrm{j}) 10 \%$ $\mathrm{D}_{2} \mathrm{O},(\mathrm{k}) \mathrm{sG} 3_{\mathrm{I}}$ in $10 \% \mathrm{D}_{2} \mathrm{O}$, (1) sG3 ${ }_{\mathrm{wt}}$ in $100 \% \mathrm{D}_{2} \mathrm{O}$, and $(\mathrm{m}) \mathrm{sG} 3_{\mathrm{I}}$ in $100 \% \mathrm{D}_{2} \mathrm{O}$. sG3 ${ }_{\mathrm{wt}}$ ( $5^{\prime}$-AGGGCUGGGCUGGGCGGGA-3') refers to a truncated version of $\mathrm{G} 3_{\mathrm{wt}}$ where one $\mathrm{G}$ from each of the two GGGG-tracts was removed to stop G-register exchange dynamics ${ }^{33}$ during NMR measurements. Underlined $\mathrm{G}$ in the $\mathrm{sG} 3_{\mathrm{wt}}$ sequence indicates site of G-to-I substitution. Imino protons of the central G-quartet remain (and often $1-2$ additional guanine imino signals from terminal G-quartets) ${ }^{34}$ after $1 \mathrm{~h}$ of sample incubation in $100 \% \mathrm{D}_{2} \mathrm{O}($ see also Figure $\mathrm{S} 6$ ).

the local structure of an RNA to an inosine-containing Gquadruplex (GI-quadruplex), a previously unreported RNA motif.

To explore different aspects of a quadruplex-forming nucleotide exchange, we examined inosine-bearing RNAs in different biological models. First, to assess whether GIquadruplexes display similar structure-function relationships as conventional quadruplexes, we studied the spinach aptamer with inosines in its G-quadruplex core. Second, to show that GI-quadruplex formation can be triggered in a natural sequence, we demonstrated a transition of stem-loop-toquadruplex folding at the splice junction of the human HLAB mRNA. Third, we uncovered evidence of putative GIquadruplexes in the human transcriptome using a state-of-theart quadruplex search algorithm. Finally, to demonstrate that GI-quadruplexes function in cells, we assayed the processing of miR-149, after inosine incorporation in its G-quadruplex motif. Our findings contribute to an emerging picture of an interplay between RNA G-quadruplex formation and post-transcriptional modification of RNA. ${ }^{25,26}$

\section{RESULTS}

Inosine Substitutes for Guanosine in RNA GQuadruplexes In Vitro. To study the properties of putative GI-quadruplexes, we used a well-characterized model sequence comprising three G-quartets $\left(\mathrm{G} 3_{\mathrm{wt}}\right) .^{27}$ We synthesized derivatives of $\mathrm{G} 3_{\mathrm{wt}}$ with adenosine or inosine at three positions in the third G-tract (Figure 1a). We then measured UVmelting curves and calculated melting temperatures $\left(T_{\mathrm{m}}\right)$ to assess the thermal stability of putative quadruplex structures. ${ }^{28}$ $\mathrm{G} 3{ }_{\mathrm{wt}}$ yielded a $T_{\mathrm{m}}$ of $74^{\circ} \mathrm{C}$ (Figure $1 \mathrm{~b}$ ). Substitution of A at flanking quartet positions $\left(\mathrm{A}_{16}, \mathrm{~A}_{18}\right)$ of $\mathrm{G} 3_{\mathrm{wt}}$ lowered the $T_{\mathrm{m}}$ by $\approx 20{ }^{\circ} \mathrm{C}$, consistent with unfolding of one of the three quartets. In contrast, A-I substitution at these positions $\left(\mathrm{I}_{16}, \mathrm{I}_{18}\right)$ raised the $T_{\mathrm{m}}$ 's by $\approx 10{ }^{\circ} \mathrm{C}$, consistent with reformation of the third quartet to attain a three-stacked GI-quadruplex. As expected, 
the most dramatic effects of inosine substitutions were seen at the central G-quartet. Whereas $\mathrm{A}_{17}$ did not fold as a Gquadruplex, $\mathrm{I}_{17}$ gave a $T_{\mathrm{m}}$ of $63{ }^{\circ} \mathrm{C}$ in a $\mathrm{K}^{+}$-dependent manner, consistent with formation of a stable GI-quadruplex (Table S1). Placement of 7-deazaguanosine at the central quartet (deaza- $\mathrm{G}_{17}$ ) abolished G-quadruplex formation (Figure 1c). In 7-deazaguanosine, $\mathrm{N}^{7}$ is replaced by $\mathrm{C}-\mathrm{H}$, which prevents Hoogsteen base pairing and therefore also stops the formation of a quartet. ${ }^{29,30}$ Pyridostatin (PDS) is a commonly used smallmolecule ligand that stabilizes rG4s by $\pi$-stacking to the face of a quartet. ${ }^{31}$ Addition of PDS to $\mathrm{I}_{16}$ and $\mathrm{I}_{17}$ also stabilized GIquadruplexes (Figure S1).

In cells, adenosines in double-stranded (stem-loop) regions are often hyper-edited in clusters, as ADAR docks onto a double-stranded region and converts local adenosines somewhat indiscriminately. ${ }^{23,32}$ Therefore, we looked at the effects of multiple A-to-I substitutions on quadruplex formation. Overall, GI-quadruplexes showed an approximate $10{ }^{\circ} \mathrm{C}$ decrease in $T_{\mathrm{m}}$ per inosine incorporation compared to unmodified $\mathrm{G} 3_{\mathrm{wt}}$ (Figure $1 \mathrm{~b}$ ), consistent with the loss of one H-bond per inosine (Figure 1a). At high RNA concentrations, some $\mathrm{rG} 4 \mathrm{~s}$ fold in trans as oligomers. We therefore measured thermal stabilities of putative GI-quadruplexes over a 10-fold range in RNA concentration (Figure S2). We found that melting temperatures were mostly independent of RNA concentrations, with the possible exception of $\mathrm{I}_{16 / 17 / 18}$, thereby confirming the intramolecular form of these RNAs. Consistently, GI-quadruplexes migrated faster than its singlestranded control $A_{16 / 17 / 18}$ during native polyacrylamide gel electrophoresis (Figure S3). We also recorded circular dichroism (CD) spectra in order to examine quadruplex topologies (Figure S4). The CD data indicated that GIquadruplexes adopt a $\mathrm{K}^{+}$-dependent parallel G-quadruplex structure, characterized by a peak at $\approx 260 \mathrm{~nm}$ and a trough at $\approx 240 \mathrm{~nm}$, in common with conventional rG4s. ${ }^{35}$

The binding of two $\mathrm{K}^{+}$-cations by $\mathrm{O}^{6}$-oxygens in the cavities of a rG4 contributes markedly to its thermal stability. ${ }^{6,36}$ Since inosine is iso-structural with guanosine, we expected that GIquadruplexes would exhibit a similar affinity for potassium ions. To confirm this, we determined the melting temperatures of two representative GI-quadruplexes as a function of $\mathrm{K}^{+}$ concentrations (Figure S5). Indeed, a plot of $T_{\mathrm{m}}$ versus $\log \left(c_{\mathrm{K}^{+}}\right)$for $\mathrm{I}_{16}$ and $\mathrm{I}_{16 / 18}$ showed a linear relationship. Notably, the decrease in stability accompanying G-I substitution was rescued by a $\approx 5$-fold increase in $\mathrm{K}^{+}$concentration, that is, within the limits of physiological potassium levels (Figure S5). The data suggested that GI-quadruplex stability in vivo may depend on intracellular $\mathrm{K}^{+}$concentrations, ${ }^{37}$ as for canonical rG4s. $^{38}$

The aforementioned data showed that GI-quadruplexes exhibit variable thermodynamic stabilities dependent on the location of the inosine. In order to gain some molecular insight on the folding/unfolding of GI-quadruplexes, we turned to temperature-controlled nanoelectrospray mass spectrometry. ${ }^{39,40}$ This method allows to infer the presence of folded intermediates at various temperatures by quantifying RNAbound $\mathrm{K}^{+}$ions. We observed that $\mathrm{G} 3_{\mathrm{wt}}$ underwent a simultaneous loss of two $\mathrm{K}^{+}$ions with increasing temperature, consistent with one-step unfolding of the quartets. $\mathrm{I}_{17}$ behaved similarly (Figure $1 \mathrm{~d}, \mathrm{e}$ ). However, $\mathrm{I}_{16}$ and $\mathrm{I}_{18}$, which have inosine at the flanking position of the quartets, showed a twostep unfolding upon melting (Figure 1f,g). Presumably, the less stable $G_{3} I$-quartet in these structures first unfolds with the loss of one $\mathrm{K}^{+}$ion to leave a two-stacked $\mathrm{rG} 4$, which thereafter releases the remaining $\mathrm{K}^{+}$ion at higher temperature.

To provide further supporting evidence for a three-stacked GI-quadruplex, we turned to NMR spectroscopy. A onedimensional ${ }^{1} \mathrm{H}$ NMR spectrum of $\mathrm{G} 3{ }_{\mathrm{wt}}$ yielded resonances around $11 \mathrm{ppm}$, which is characteristic for Hoogsteen imino proton resonances in G-quadruplex formation ${ }^{34,41,42}$ (Figure S6a). However, more than the 12 expected resonances for a three-layer G-quadruplex structure were visible, indicating some conformational heterogeneity, possibly due to additional guanosines in the two G4 motifs of $\mathrm{G} 3_{\mathrm{wt}}$ or intermolecular structures at the high RNA concentration. In order to simplify the interpretation of these data, we truncated and removed two guanosines from $\mathrm{G} 3_{\mathrm{wt}}$ to give $\mathrm{sG} 3_{\mathrm{wt}}$, containing only GGGtracts ( $5^{\prime}$-AGGGCUGGGCUGGGCGGGA-3'). Indeed, $s G 3_{w t}$ now showed the 12 expected resonances (Figures $1 j$ and S6b). A G-for-A substitution in the central G-quartet attenuated the sharp signals in this region $\left(\mathrm{sG}_{\mathrm{A}}\right.$, Figure $\left.\mathrm{S} 6 \mathrm{c}\right)$, consistent with no stable formation of an intramolecular quadruplex. However, G-for-I substitution $\left(\mathrm{sG}_{\mathrm{I}}\right)$ yielded 12 main and 3 minor discernible sharp signals at $10.5-12 \mathrm{ppm}$, consistent with the presence of a three-layer GI-quadruplex (Figures $1 \mathrm{k}$ and S6d). We cannot explain two small resonances around $14 \mathrm{ppm}$, which might belong to an additional structure involving Watson-Crick base pairing.

In an effort to identify the inosine-derived signals in the spectra of $\mathrm{sG}_{3}$, we adopted a strategy described by Adrian et al., who reported how ${ }^{1} \mathrm{H}$ NMR spectra of G-quadruplexes performed in $100 \% \mathrm{D}_{2} \mathrm{O}$ showed loss of most of the guanine imino signals in the exposed upper and lower quartets of a Gquadruplex. $^{34}$ Indeed, consistent with their findings, $\mathrm{D}_{2} \mathrm{O}$ spectra of $s 3_{w t}$ and $s G 3_{I}$ showed five sharp signals (Figures $11, \mathrm{~m}$ and $\mathrm{S} 6 \mathrm{e}-\mathrm{g}$ ), which taken together unambiguously confirmed inosine involvement in the central quartet of GIquadruplex sG3 .

GI-Quadruplexes Are Functional. Next, we attempted to show that GI-quadruplexes are functional. Spinach is a wellstudied RNA aptamer, ${ }^{43}$ comprising a metastable two-stacked rG4 that folds in a complex topology involving two Gdinucleotides and four interspaced guanosines. ${ }^{9}$ It is stabilized after stacking of the fluorophore 3,5-difluoro-4-hydroxybenzylidene imidazolinone (DFHBI) to the upper face of one Gquartet (Figure 2a,b). G-to-A substitutions in the quadruplex at $\mathrm{G}_{44}$ and $\mathrm{G}_{14}$ abolish its folding and also DFHBI binding, leading to loss of fluorescence emission. ${ }^{9,44}$ We performed Gto-A exchange at four additional sites $\left(A_{10}, A_{15}, A_{41}, A_{46}\right)$ to confirm their participation in quadruplex folding. As expected, fluorescence was abolished in all cases except $A_{15}$, which binds DFHBI, but is not part of a G-quartet ${ }^{9}$ (Figure $2 b, c$ ). We then examined whether A-to-I substitutions at these sites could induce aptamer refolding.

Fluorescence was re-established most strongly for $\mathrm{I}_{44}$, followed by $\mathrm{I}_{14}$ and $\mathrm{I}_{46}$, which suggested that all three variants formed GI-quadruplexes resembling the WT-aptamer (Figure $2 c$ ). The effects of metal cations on fluorescence emission of these derivatives were also supportive of GI-quadruplex folding. The fluorescence emission of spinach WT and $\mathrm{I}_{44}$ was increased markedly by higher potassium concentrations (Figure $2 \mathrm{~d}$ ), with calculated apparent $K_{\mathrm{d}}$ values of $9.8 \pm 1.0$ $\mathrm{mM}$ and $45.1 \pm 1.7 \mathrm{mM}$, respectively. Of note, both spinach $\mathrm{WT}$ and $\mathrm{I}_{44}$ showed a positive folding cooperativity (Hill coefficients, $1.8 \pm 0.1$ and $1.7 \pm 0.3$, respectively), reminiscent 

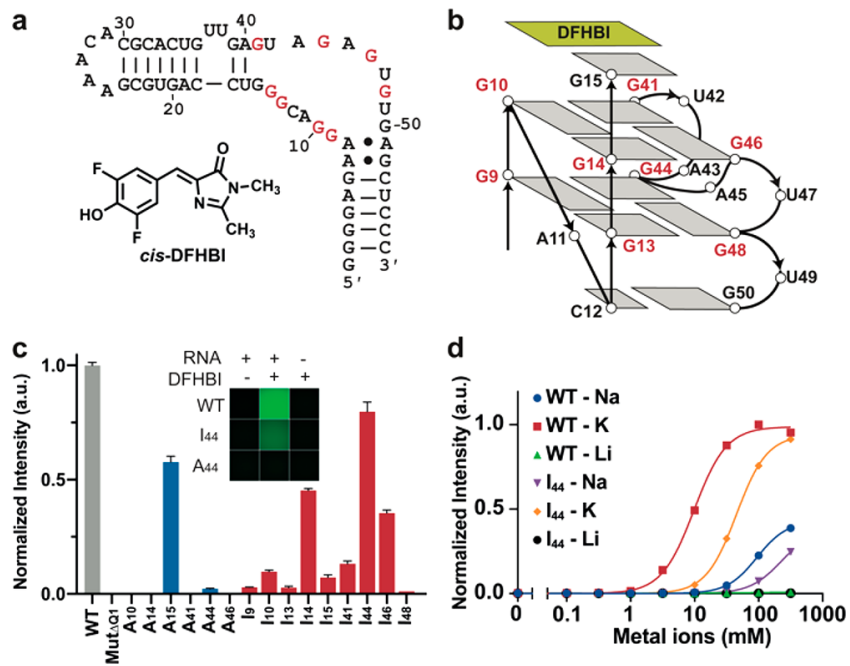

Figure 2. GI-quadruplex function in the spinach aptamer. (a) Secondary structure of spinach $\mathrm{WT}^{9}$ (G's participating in quadruplex are marked in red) and chemical structure of its ligand DFHBI. (b) Gquadruplex observed in the spinach aptamer; ${ }^{9}$ DFHBI stacks to the upper face of the quadruplex and forms hydrogen bonds with $G_{15}$ as well as surrounding $2^{\prime}$-hydroxyl groups. (c) Fluorescent emission of inosine-substituted spinach mutants; Mut $_{\Delta \mathrm{Q} 1}$ has the lower G-quartet mutated to pyrimidines; ${ }^{9}$ data represent mean values + SEM from three measurements. Inset shows fluorescence microscopy in $100 \mathrm{mM}$ $\mathrm{K}^{+}$for spinach mutants with or without DFHBI. (d) Fluorescence emission of spinach WT and $\mathrm{I}_{44}$ as a function of $\mathrm{Na}^{+}, \mathrm{K}^{+}$, or $\mathrm{Li}^{+}$ concentrations; data represent mean from three measurements and are fitted to the Hill equation.

of the positive folding cooperativity of some two-stacked rG4s. ${ }^{45}$

A standard means to detect rG4s in native RNAs is a partial or full block in reverse transcription, since reverse transcriptase (RT) cannot progress past a thermodynamically stable Gquadruplex. Stalling is detected by RNA sequencing and occurs one nucleotide after the rG4 $3^{\prime}$-end. ${ }^{46,47}$ To determine whether GI-quadruplexes fold in natural inosine-containing transcripts and if they can be detected by reverse transcriptase stalling (RTS), we analyzed a $\approx 100$ nt-long region around the exon4/intron4 splice junction of human HLA-B. During splicing, U1 snRNA hybridizes at nucleotide positions -3 to +6 , where A-to-I editing has also been observed (positions -7 , +3 , and +4$).{ }^{23}$ An mfold analysis ${ }^{48}$ of this region suggested that it forms a double-stranded structure (Figure 3a). Notably, the downstream region bears nine highly conserved G-tracts (Figure 3b). Multimeric G-repeats are a common feature of rG4-rich regions in native RNAs. This may allow various combinations of two- and three-stacked rG4s to form, ${ }^{47,49}$ in dynamic equilibria with one another. The presence of equilibrating structures confounds the biophysical analysis of such sequences in vitro. Nevertheless, we synthesized three 20nt sequences corresponding to the $5^{\prime}$-end of this transcript, bearing the three edited sites (R-20 ${ }_{\mathrm{wt}}$ : wild-type; R-20 $0_{\mathrm{I}}$ : A-to-I substituted; R-20 $\mathrm{G}$ : A-to-G mutated, as control). We then measured the melting temperatures of these $\mathrm{G}$-rich sequences. $\mathrm{R}-20_{\mathrm{wt}}$ showed a $T_{\mathrm{m}}$ of $51{ }^{\circ} \mathrm{C}$, consistent with the presence of quadruplexes in this region. However, A-to-G substitution at the three editing positions $\left(\mathrm{R}-20_{\mathrm{G}}\right)$ raised this $T_{\mathrm{m}}$ by $15{ }^{\circ} \mathrm{C}$, whereas A-to-I substitution increased it by $7{ }^{\circ} \mathrm{C}\left(\mathrm{R}-20_{\mathrm{I}}\right)$. Taken together, these data are consistent with editing-induced formation of GI-quadruplex structures (Figure S7).

Next, we performed RT-stop assays with full-length variants of this region from HLA-B (R-99 ${ }_{w t}$ R-99, R-99 ; Figure 3a). To site-specifically introduce inosines in R-99, we used a semisynthetic protocol (Figure S8). RT-stop patterns were analyzed under quadruplex-stabilizing $(150 \mathrm{mM} \mathrm{KCl})$ and -nonstabilizing conditions $(150 \mathrm{mM} \mathrm{LiCl})$. In lithiumcontaining buffer, reverse transcription of the sequences yielded predominantly full-length cDNAs, shown by the peak centered at $150 \mathrm{nt}$ (Figure $3 \mathrm{c}-\mathrm{e}$ ). However, the RT outcome was markedly different in the presence of potassium. R-99 yielded weak $\mathrm{K}^{+}$-dependent RT-stops at G-tracts correspond-
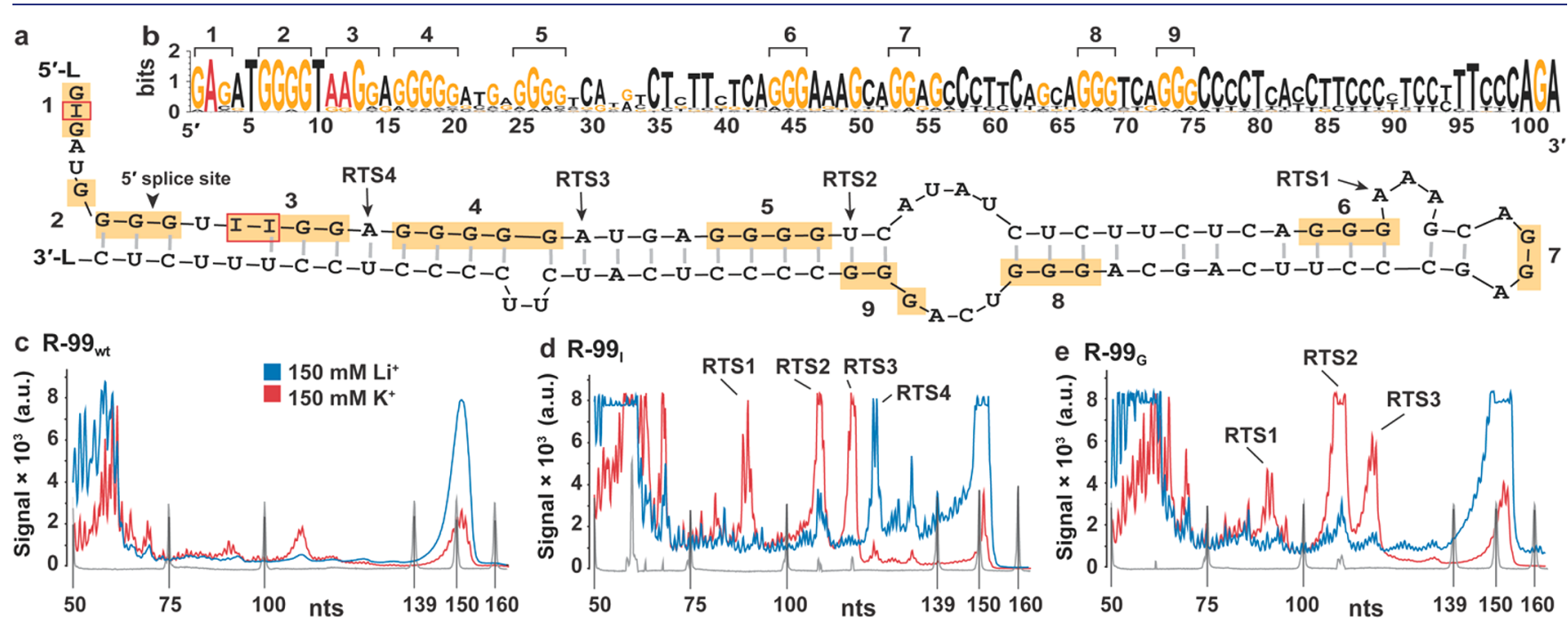

Figure 3. GI-quadruplex function in the human HLA-B exon4/intron4 splice junction. (a) Predicted ${ }^{48}$ secondary structure of the RT construct with three inosine modifications (red frames). Conserved G-tracts are highlighted with yellow. L stands for linker (sequences described in Methods). (b) Sequence conservation of HLA-B splice junction (exon4/intron4) across 39 eutherian mammals; editing positions from RADAR

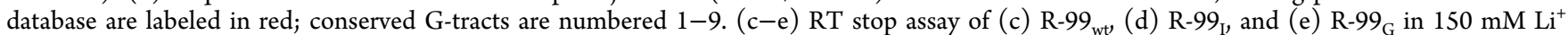
(blue trace) or $150 \mathrm{mM} \mathrm{K}^{+}$(red trace). A 35-500 nt size standard was used as a ladder (gray trace). Strong RT stop sites are annotated as indicated in (a). 
ing to RTS1 and RTS2. Therefore, adenosines interrupting Gtracts 1 and 3 interfere with the formation of a stable G3quadruplex in the $5^{\prime}$-arm (Figure $3 \mathrm{a}$ ). In contrast, the positive control R-99 ${ }_{\mathrm{G}}$ showed three strong RT-stop sites localized at $94 \mathrm{nt}$ (RTS1), $112 \mathrm{nt}$ (RTS2), and $120 \mathrm{nt}$ (RTS3). These were immediately upstream of the $3^{\prime}$-end of G-tracts, consistent with their participation in quadruplex folds (Figure 3a). The detection of multiple RT-stop sites suggests that multiple rG4s may fold from different G-tracts under the assay conditions, as discussed previously. ${ }^{47,49}$ Pleasingly, R-99 y yielded a highly similar profile to that of $\mathrm{R}-99_{\mathrm{G}}$. Interestingly, R-99 $\mathrm{I}$ also showed a lithium-specific RT-stop at approximately $126 \mathrm{nt}$ (RTS4), where editing transforms an AAGG motif into IIGG, which we cannot explain. Taken together, the data provide evidence that A-to-I substitutions can promote GI-quadruplex formation at this splice junction of HLA-B. Furthermore, editing at positions +3 and +4 would be expected to weaken the overall stability of the stem-loop, possibly initiating the conformational switch to the quadruplex during reverse transcription. It is tempting to speculate that editing-induced quadruplex folding influences splicing at this locus, in analogous fashion to that reported for some rG4s. ${ }^{50,51}$ However, editing also changes the base-pairing register of the splice-recognition motif, so it would be difficult to separate the effects of quadruplex folding from the potential reduction of U1 snRNA binding.

Transcriptome-Wide Formation of GI-Quadruplexes. We reasoned that A-to-I editing might activate latent GIquadruplexes to strengthen G-quadruplex-rich local structure in a similar fashion to its effects on the HLA-B splice junction. Thus, we examined the sequence context of 2.5 million validated A-to-I editing sites from the RADAR database. ${ }^{52}$ We used an inosine-adapted version of pqsfinder ${ }^{53}$ (see Methods) to search for putative GI-quadruplex-forming sequences (PIQS) across edited UTRs, that are typically enriched for A-to-I editing and functional associations of G-quadruplexes. ${ }^{54}$ Pqsfinder is a well-used algorithm that predicts conventional putative G-quadruplex-forming sequences (PQS) by identifying four consecutive G-tracts and assigning a quantitative score, which is based on the number of G-quartets, loop length, and imperfections (bulges, mismatches). ${ }^{53}$ We identified $>600$ and 29 three-stacked PIQS in $3^{\prime}$ UTRs and $5^{\prime}$ UTRs, respectively, possibly signaling a widespread potential for GI-quadruplex formation in regulating mRNA metabolism (Figure S9 and Supplementary Data Table 1).

GI-Quadruplexes Phenocopy Canonical rG4s during miRNA Processing in Cells. In an effort to provide evidence that a GI-quadruplex is functional in cells, we turned to a previously described system involving the biogenesis of an unusual miRNA precursor (pre-miRNA) ${ }^{55,56}$ Pre-miRNAs are stem-loop structures that are cleaved by the RNase Dicer, yielding a duplex comprising guide and passenger strands. ${ }^{57}$ The passenger arm of pre-miR149 comprises several G-tracts that may form multiple rG4s (Figure 4a). This alters the structure away from the stem-loop that is recognized by Dicer, leading to reduced miR149 activity in cells (Figure 4b). Using UV melting and CD experiments (not shown), we confirmed the original report that the passenger strand $\left(\mathrm{R}-18_{\mathrm{G}}\right)$ of premiR149 folds into a stable rG4(s) $\left(T_{\mathrm{m}}=74{ }^{\circ} \mathrm{C}\right.$; Figure $\left.4 \mathrm{c}\right)$. When $\mathrm{G} 48$ in $\mathrm{R}-18_{\mathrm{G}}$ was exchanged for adenosine $\left(\mathrm{R}-18_{\mathrm{A}}\right)$, the $T_{\mathrm{m}}$ decreased by almost $20{ }^{\circ} \mathrm{C}$, consistent with the loss of a highly stable G3-quadruplex. However, inosine at this site

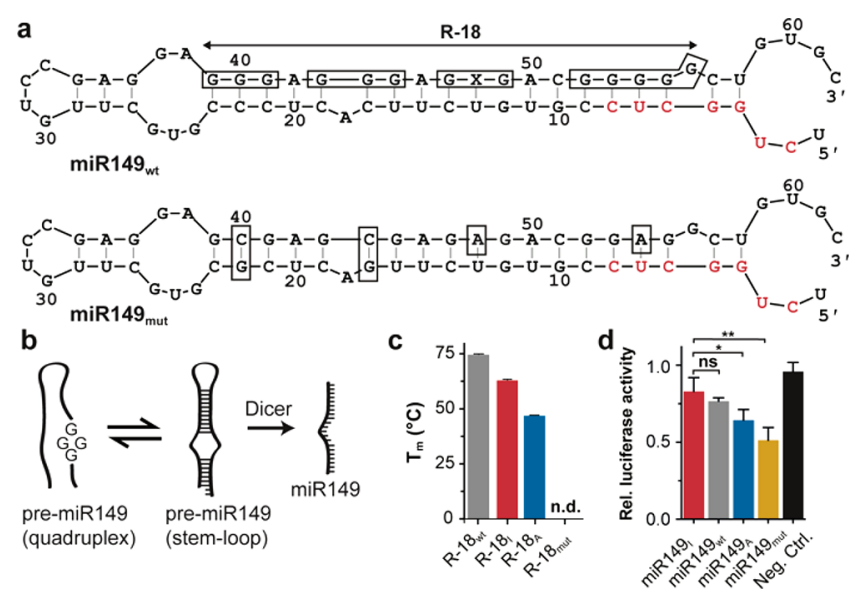

Figure 4. GI-quadruplexes phenocopy G-quadruplexes during miRNA processing in cells. (a) Predicted secondary structure for WT and Mut variants of pre-miR149. G-tracts in the passenger strand and sites of mutations are boxed. X indicates G-to-I or G-to-A substitutions. Seed region of miR149 guide spans nucleotides 2-8 (red font). (b) Model of quadruplex formation inhibiting Dicer processing. (c) Melting temperatures of R-18 variants in $3 \mathrm{mM} \mathrm{KCl}$. Data represents mean + $\mathrm{SD}$ from three experiments. (d) Dual reporter luciferase assay of constructs bearing a target site for miR149 in the ZBTB2 gene. ${ }^{58}$ Reporter activity represents Renilla/firefly values normalized to $0 \mathrm{nM}$ treatment. Data expressed as mean $+\mathrm{SD} * P \leq 0.05$, $* * P \leq 0.01(t$ test), $N=3$.

showed a much higher thermal stability $\left(\mathrm{R}-18_{\mathrm{I}} ; T_{\mathrm{m}}=62{ }^{\circ} \mathrm{C}\right)$, consistent with formation of a GI-quadruplex.

Next, we synthesized A-, I- and G-variants of full-length premiR149 (pre-miR149A, pre-miR149, pre-miR149 ${ }_{\mathrm{wt}}$, respectively; Figure 4a) and investigated RNA secondary structure by CD spectroscopy (Figure S10), which can be used to study complex hairpin-quadruplex equilibria. ${ }^{26,59}$ The CD data suggested the presence of a quadruplex-hairpin equilibrium with a strong $\mathrm{K}^{+}$-stabilizing effect for the quadruplex conformation in pre-miR $149_{\mathrm{wt}}$ and pre-miR149, but not for pre-miR149 $\left(T_{\mathrm{m}}\right.$ increase of $21{ }^{\circ} \mathrm{C}, 24{ }^{\circ} \mathrm{C}$, and $13{ }^{\circ} \mathrm{C}$, respectively). Then, we tested these pre-miR149 variants in a sensitive reporter assay in order to compare the activity of the miR149 guide strand produced from the three variants. The reporter assay was validated using pre-miR $149_{\text {mut }}$ in which six nucleotides were mutated so as to prevent $\mathrm{rG} 4$ formation in the pre-miRNA, as described previously. ${ }^{56}$ Hence, cotransfection of the reporter plasmid with pre-miR $149_{\text {mut }}$ into HEK293T cells inhibited luciferase by about 50\% (Figure 4d). Pre-miR149 ${ }_{\mathrm{wt}}$ showed only minor inhibition of luciferase, consistent with prevention of its processing by $\mathrm{rG} 4 \mathrm{~s} .^{55}$ Whereas pre-miR149 A inhibited luciferase activity, premiR149 I was inactive, consistent with inosine at the core of a GI-quadruplex(es) that blocks pre-miR149 processing. To confirm that effects detected in reporter assay originated from inhibitory quadruplexes, we tested in vitro Dicer processing of 5 - ${ }^{32}$ P-labeled pre-miR-149 $/$ wt $/$ re-miR-149 $/$ /pre-miR-149 $9_{\text {mut }}$ in the presence of $\mathrm{Li}^{+}(150 \mathrm{mM})$ or physiological $\mathrm{K}^{+}$levels $(150$ $\mathrm{mM})$. Cleavage to mature RNAs was assessed on a denaturing polyacrylamide gel and quantified for both $\mathrm{Li}^{+}$and $\mathrm{K}^{+}$ conditions (see Methods for details). Consistent with the cell-based results (Figure $4 \mathrm{~d}$ ), we observed a $\mathrm{K}^{+}$-dependent inhibitory role of $\mathrm{rG} 4 \mathrm{~s}$ in pre-miR $149_{\mathrm{wt}}$ and pre-miR149, which effect was consistently stronger than observed for the non-rG4 control pre-miR149 ${ }_{\text {mut }}$ across replicates (Figure S11). 
Taken together, the results provided supporting evidence that GI-quadruplexes may show similar effects in cells to those of conventional rG4s.

\section{DISCUSSION}

In cells, RNAs are present as assemblies of dynamic conformational states that are stabilized by secondary and tertiary interactions. ${ }^{11,60}$ Different states may be regulated separately with consequences for gene expression. ${ }^{61}$ Changes in RNA conformations can be triggered by the actions of helicases and other RNA-binding proteins, by small metabolites such as polyamines ${ }^{62}$ and also by variations in salt concentrations or temperatures. RNA conformations are also affected by post-transcriptional modifications such as methylation $^{26,63}$ or A-to-I editing. ${ }^{18-20}$

To date, genome-wide methods have identified thousands of putative rG4 motifs in transcriptomes. ${ }^{1,2}$ One pertinent example is rG4s that contain G-quartets with vacant G-sites that can be filled in trans, for example, with guanosine nucleotides. ${ }^{64}$ We postulated that since most of the thermodynamic stability of an rG4 derives from coordinating potassium, ${ }^{65}$ it would tolerate the loss of exocyclic amino groups from guanosine bases; in other words, inosine could substitute for guanosine in G-quartets. Our understanding of the properties of the basic rG4 derives from the study of simple chemically synthesized structures in vitro. However, rG4 structure/function in vivo is markedly more complex. For example, native RNAs usually carry more than four G-tracts in quadruplex regions that permit folding of distinct rG4s (Figure $3 \mathrm{a}, \mathrm{b})$, likely in equilibrium with one another; ${ }^{49,62} \mathrm{rG} 4$ folding is influenced by RNA-binding proteins; ${ }^{66,67}$ and natural quadruplex topologies can be exquisitely intricate (cf. the spinach aptamer). ${ }^{8}$

Using a well-characterized rG4 model sequence, we synthesized analogs containing inosines and confirmed their folding to GI-quadruplexes using conventional biophysical techniques. We found that GI-quadruplexes were unimolecular, they tolerated multiple inosine insertions, and their stability was potassium-dependent under physiological conditions (Figure 1). This led us to postulate that GI-quadruplexes might be formed after A-to-I editing events. In this way, a new class of latent RNA quadruplex structure might be activated by the action of ADAR in vivo.

The dynamic folding/unfolding of $\mathrm{rG} 4 \mathrm{~s}$ lends itself to participation in equilibria with other secondary structures. Indeed, rG4s have been observed to colocate with hairpin forming sequences, ${ }^{42,56,68}$ and in some cases, conformational transitions between the two structures are proposed to regulate biological functions. ${ }^{26,55,69}$ Since ADAR modifies and unwinds double-stranded RNA, ${ }^{13,70}$ our data suggest an interplay between stem-loop and quadruplex structures. Furthermore, as editing occurs in clusters and transforms $\mathrm{A}-\mathrm{U}$ base pairs into I-U mismatches, it may lead to a stem-loop progressively opening so as to facilitate folding into a thermodynamically stable GI-quadruplex. We have shown previously (A.B.) that Ato-I editing causes widescale conformational changes in the transcriptome in the context of Watson-Crick base-pairing. ${ }^{18}$ We propose here an alternative mechanism by which the conformational landscape of an RNA could be switched, with potentially important functional consequences at sites where the editing in transcripts occurs at significant levels. ${ }^{52}$

We searched for supporting evidence for this mechanism in a natural RNA, at a splice junction of human HLA-B, which bears three validated editing sites among a large number of Gtracts. RT-stop assays confirmed the formation of GIquadruplex structures in similar fashion to that observed for rG4 controls. To enable this in vitro study of a $\approx 100$ nt-long natural RNA region, we used a semisynthetic protocol, which allows site-specific incorporation of inosines in long RNAs $(>150 \mathrm{nt})$. We expect this protocol to be of considerable value in future A-to-I editing studies. Finally, we uncovered evidence of putative GI-quadruplexes in the human transcriptome using an inosine-specific quadruplex search algorithm (Figure S9). We identified a strong preference of PIQS in $3^{\prime}$ UTRs compared to $5^{\prime}$ UTRs and speculate that these PIQS may be linked to functional roles similar to rG4s present in UTRs of mRNAs. ${ }^{2,54}$ Further studies are needed to solidify the functional importance of GI-quadruplexes in the transcriptome.

\section{METHODS}

RNA Sample Preparation. A library of oligoribonucleotides was prepared, including all possible combinations of G-to-I and G-to-A substitutions within the third G-tract $\left(\mathrm{G}_{16} \mathrm{G}_{17} \mathrm{G}_{18}\right)$ of the model sequence 5'-AAAAGGGCUGGGGCUGGGCGGGGA-3' (Figure 1a). To indicate the site and nature of the substitution, we referred to the position in the sequence according to Figure 1a, for example, $\mathrm{I}_{16}$ indicates a G-to-I substitution at position 16 in the sequence. For the work with modified spinach, we synthesized a library of oligoribonucleotides encompassing all possible G-to-I substitutions of guanines that are participating in the G-quadruplex, based on the "spinach 5 bp P1 stem truncation mutant", previously reported by Huang et al. ${ }^{9}$ Oligoribonucleotides were prepared under standard conditions on a MerMade 12 synthesizer (Bioautomation Corporation) using Universal UnyLinker Support (Controlled Pore Glass, CPG, 500, 1000, or $2000 \AA$, ChemGenes) and standard RNA phosphoramidites (Thermo Fisher Scientific). For incorporation of inosine and 7-deazaguanosine, the commercially available phosphoramidites from ChemGenes were used (cat. no. ANP-5680, ANP7301). For cleavage from solid support and removal of base protecting groups, CPG was exposed to gaseous methylamine at $65^{\circ} \mathrm{C}$ and 1.2 bar for $90 \mathrm{~min}$. After eluting the oligoribonucleotides with ethanol/ water (1:1), dry oligoribonucleotides were subjected to desilylation using freshly prepared 1-methyl-2-pyrrolidone, triethylamine (TEA), and TEA.3HF (6:3:4) for $2 \mathrm{~h}$ at $70{ }^{\circ} \mathrm{C}$. Ethoxytrimethylsilane was added, and the crude oligoribonucleotides were precipitated from diisopropylether. The crude RNA was purified by RP-HPLC (Agilent 1200 Series; Agilent Technologies). Dimethoxytrityl (DMT) groups were cleaved using $40 \%$ acetic acid for $20 \mathrm{~min}$ at room temperature. For the DMT-off purification of the RNAs, again RP-HPLC with a Waters XBridge OST C18 column $\left(10 \times 50 \mathrm{~mm}, 2.5 \mu \mathrm{m}, 65^{\circ} \mathrm{C}, 0.3\right.$ $\mathrm{mL} / \mathrm{min}$ ) was used. Purified products were characterized on an Agilent 6130 Series Quadrupole LC/MS (Agilent Technologies) on a Waters Acquity OST C18 column $\left(2.1 \times 50 \mathrm{~mm}, 1.7 \mu \mathrm{m}, 65^{\circ} \mathrm{C}, 0.3\right.$ $\mathrm{mL} / \mathrm{min}$ ). For quantification of the RNAs, UV absorbance at $260 \mathrm{~nm}$ was measured with Nanodrop 2000 (Thermo Fisher Scientific).

Circular Dichroism Spectroscopy. CD spectra were recorded between 200 and $320 \mathrm{~nm}$ on a Jasco J-710 spectropolarimeter. The buffer subtracted average of three consecutive CD scans $(20 \mathrm{~nm} / \mathrm{min}$, $4 \mathrm{~s}$ response time, $0.5 \mathrm{~nm}$ data pitch, $2 \mathrm{~nm}$ bandwidth, light path 1 $\mathrm{mm}$ ) is given. Prior to CD measurements, the RNAs were prepared at a concentration of $4 \mu \mathrm{M}$ in $10 \mathrm{mM}$ lithium cacodylate, $10 \mathrm{mM} \mathrm{KCl}$, $\mathrm{pH} \mathrm{7.2,} \mathrm{heated} \mathrm{for} 5 \mathrm{~min}$ at $95{ }^{\circ} \mathrm{C}$, and then progressively cooled down to room temperature for $60 \mathrm{~min}$ before to be equilibrated at 4 ${ }^{\circ} \mathrm{C}$ for $>1 \mathrm{~h}$. For melting experiments, samples were heated from 20 to $95{ }^{\circ} \mathrm{C}\left(1{ }^{\circ} \mathrm{C} / \mathrm{min}\right)$, and the $\mathrm{CD}$ at $265 / 263 \mathrm{~nm}$ was measured every $0.5^{\circ} \mathrm{C}$. Pyridostatin (PDS) pentahydrochloride (TOCRIS, cat. no. 4763 ), was added to a final concentration of $8 \mu \mathrm{M}$, which results in an RNA:PDS ratio of 1:2. Raw data and first derivative plots were smoothed using a Savitzky-Golay filter (convolution width 25). 
UV Melting. Thermal melting was performed using a Varian Cary 300 spectrophotometer. RNA samples at various concentrations were prepared in $10 \mathrm{mM}$ lithium cacodylate, $\mathrm{pH} 7.2$ at the indicated concentration of $\mathrm{KCl}$. The samples were heated for $5 \mathrm{~min}$ at $90{ }^{\circ} \mathrm{C}$, then cooled down to $20^{\circ} \mathrm{C}$, and heated again to $90{ }^{\circ} \mathrm{C}\left(0.2^{\circ} \mathrm{C} / \mathrm{min}\right)$, repeating the melting process three times. The absorbance at a wavelength of $295 \mathrm{~nm}$ was recorded every $0.2{ }^{\circ} \mathrm{C}$. Thermodynamic parameters were calculated using a two-state equilibrium analysis as described in ref 28 by using the van't Hoff representation $\left(\ln \left(K_{\mathrm{a}}\right)\right.$ versus $1 / T$ ) according to eq 1 , assuming that $\Delta C_{\mathrm{p}}{ }^{\circ}=0 . \Delta H^{\circ}, \Delta S^{\circ}$, and $\Delta G^{\circ}$ are given at $37^{\circ} \mathrm{C}$.

$$
\ln \left(K_{\mathrm{a}}\right)=-\frac{\Delta H^{\circ}}{R T}+\frac{\Delta S^{\circ}}{R}
$$

The melting temperature $\left(T_{\mathrm{m}}\right)$ was calculated from the average of three consecutive buffer-subtracted melting runs by following the 4 steps below:

(1) First the upper and lower baseline were determined according to eqs 2 and (3):

$$
\text { upper baseline ("folded state"): } A_{\mathrm{F}}(T)=A_{\mathrm{F}}^{0}+m_{\mathrm{F}} \times T
$$

lower baseline ("unfolded state"): $A_{\mathrm{U}}(T)=A_{\mathrm{U}}^{0}+m_{\mathrm{U}} \times T$

(2) Having determined the upper and lower baselines, the absorbance versus temperature plot was converted into a "fraction folded" versus temperature plot according to eq 4 .

fraction folded: $f(T)$

$$
=\left[A(T)-A_{\mathrm{U}}(T)\right] /\left[A_{\mathrm{F}}(T)-A_{\mathrm{U}}(T)\right]
$$

(3) $f(T)$ was fitted to the Boltzmann eq 5, where $A, B, C$, and $D$ are constants:

$$
f_{\text {calc }}(T)=B+\frac{A-B}{1+\mathrm{e}^{T-C / D}}
$$

(4) The melting temperature $\left(T_{\mathrm{m}}\right)$ was obtained as the temperature $(T)$ where the second derivative of the Boltzmann equation equals zero $\left(f_{\text {calc }}^{\mathrm{II}}(T)=0\right)$.

Regarding the $\mathrm{K}^{+}$dependency experiments, preliminary measurements at different $\mathrm{K}^{+}$concentrations indicated that the linear range of the tested G-to-I variant starts only at higher $\mathrm{K}^{+}$concentrations (approximately $>0.6 \mathrm{mM} \mathrm{K}{ }^{+}$). Moreover, the unmodified sequence was too stable to be fully unfolded $>3 \mathrm{mM} \mathrm{K}$, limiting the upper $\mathrm{K}^{+}$ concentration for this sequence. Thus, more than five different $\mathrm{K}^{+}$ concentrations within the linear range of the individual oligoribonucleotides were measured, and the data points were subjected to linear regression.

Native Polyacrylamide Gel Electrophoresis. $12.5 \mathrm{pmol}$ of RNA was incubated for $5 \mathrm{~min}$ at $95{ }^{\circ} \mathrm{C}$ in $50 \mathrm{mM}$ Tris- $\mathrm{HCl}, \mathrm{pH} 7.5$, $10 \mathrm{mM} \mathrm{KCl}$ or LiCl. Samples were slowly cooled down to $10{ }^{\circ} \mathrm{C}$ over $90 \mathrm{~min}$. Before samples were separated on a $15 \%$ nondenaturing polyacrylamide gel at $4{ }^{\circ} \mathrm{C}$, gel loading buffer was added to a final concentration of $15 \%$ sucrose, $0.02 \%$ Orange G. The salt concentration was kept constant at $10 \mathrm{mM} \mathrm{LiCl}$ or $\mathrm{KCl}(1)$ at the annealing step, (2) inside the polyacrylamide gel, and (3) in the Tris/ borate/EDTA running buffer. A miRNA marker (New England Biolabs, \#N2102S) was used as a reference. Bands were stained with SYBR Gold (Thermo Fisher Scientific, \#S11494) according to the manufacturer's instructions.

Dicer Processing Assay. The protocol was adapted from ref 71 . After $5^{\prime}$-end radioactive labeling, purified RNAs (100 fmol) were annealed in $150 \mathrm{mM} \mathrm{KCl} / \mathrm{LiCl}, 3 \mathrm{mM} \mathrm{MgCl}, 1 \mathrm{mM} \mathrm{ATP}, 40 \mathrm{mM}$ Tris- $\mathrm{HCl}(\mathrm{pH} 7.5)$. To this end, samples were heated for $1.5 \mathrm{~min}$ at $95{ }^{\circ} \mathrm{C}$, cooled for $1.5 \mathrm{~h}$ at room temperature, and stored on ice. After addition of 300 fmol recombinant human dicer 1 (TP319214, Origene), the reaction was incubated for $1 \mathrm{~h}$ at $37{ }^{\circ} \mathrm{C}$. Processed RNAs were separated on a $12 \%$ denaturing TBE-urea polyacrylamide gel with a labeled RNA marker $(22,25,60 \mathrm{nt})$ as a reference. Radioactive signals were visualized with a phosphor screen overnight and recorded with a Typhoon FLA7000 phosphor imager. PremiRNA processing was calculated as the fraction of processed miRNA/total RNA. The ratio of processed miRNA in $\mathrm{KCl}$ relative to $\mathrm{LiCl}$ was calculated to show salt dependence.

NMR Spectroscopy. RNA was prepared to a concentration of 0.1 $\mathrm{mM}$ in $10 \mathrm{mM}$ lithium cacodylate, $1 \mathrm{mM} \mathrm{KCl}, \mathrm{pH}$ 5.8. After heating to $95{ }^{\circ} \mathrm{C}$ for $5 \mathrm{~min}, \mathrm{KCl}$ was added to a final concentration of $25 \mathrm{mM}$. The samples were then progressively cooled down to room temperature for $60 \mathrm{~min}$ before to be stored on ice. Prior to measurements, $\mathrm{D}_{2} \mathrm{O}$ was added to a final concentration of $10 \%$. Onedimensional watergate ${ }^{1} \mathrm{H}$ NMR spectra were recorded at $298 \mathrm{~K}$ on Bruker AVIII-600 MHz spectrometer equipped with a cryoprobe. Topspin 4.0.7 (Bruker) was used for data processing. For experiments investigating protected imino protons in $100 \% \mathrm{D}_{2} \mathrm{O}$, samples were lyophilized and redissolved in $100 \% \mathrm{D}_{2} \mathrm{O}$. After $1 \mathrm{~h},{ }^{1} \mathrm{H}$ NMR spectra were recorded with similar settings as for the measurements in $10 \%$ $\mathrm{D}_{2} \mathrm{O}$.

Spinach Fluorescence Assay. RNA was folded at a concentration of $5 \mu \mathrm{M}$ by: (1) heat treatment for $1 \mathrm{~min}$ at $90^{\circ} \mathrm{C}$ in distilled deionized water, (2) incubation for $20 \mathrm{~min}$ at $50{ }^{\circ} \mathrm{C}$ in folding buffer (10 mM Tris-HCl, pH 7.5, $100 \mathrm{mM} \mathrm{KCl,} 5 \mathrm{mM} \mathrm{MgCl}$ ), and (3) a final incubation for $30 \mathrm{~min}$ at $37^{\circ} \mathrm{C}$ after addition of DFHBI (final concentration $20 \mu \mathrm{M}$ ). Fluorescence (emission at $502 \mathrm{~nm}$ ) was measured after excitation at $468 \mathrm{~nm}$ in black 384-well plates (cat. no. 3821, Corning) on a Tecan Spark $20 \mathrm{M}$ plate reader at room temperature. The bandwidth was set to $5 \mathrm{~nm}$. The data are normalized to fluorescence of the spinach WT RNA and represented as the average of triplicates. As a non-G-quadruplex forming control, we used $\mathrm{Mut}_{\triangle \mathrm{Q} 1}$ (5'-GGGGAGAAGCACGUGUCCAGUGCGAAACACGCACUGUUGACUAGAUUGUGAGCUCCC-3'), where the first G-quartet layer is mutated to pyrimidines. ${ }^{9}$ For the titration with different metal ions, the folding buffer was prepared without $\mathrm{KCl}$ and the desired amount of salts $(\mathrm{NaCl}, \mathrm{LiCl}$ or $\mathrm{KCl})$ added separately to give a concentration range from $0-1000 \mathrm{mM}$ for every metal cation. The binding curves were fitted to the Hill equation using Prism 8 $\left(\right.$ GraphPad): $Y=Y_{\max } \times[\text { ligand }]^{h} /\left(K_{\mathrm{d}}^{h}+[\text { ligand }]^{h}\right)$, where $K_{\mathrm{d}}$ is the concentration needed to achieve a half-maximum binding at equilibrium, $h$ is the Hill slope, and $Y_{\max }$ is the maximum fluorescence signal after normalization. Calculated parameters $h$ and $K_{d}$ are given \pm SEM. For the fluorescence measurement using the Leica DMI600 wide field fluorescence microscope, we prepared the RNA at a concentration of $1.2 \mu \mathrm{M}$ as described above.

Preparation of RNA Constructs for RT Stop Assay. Flanking $5^{\prime}$ and $3^{\prime}$ linker sequences were adapted from previous RNA footprinting reports. ${ }^{56,72}$ Relevant sequence information is provided in Table S2. To synthesize the R- $99_{\mathrm{wt}}$ and $\mathrm{R}-99_{\mathrm{G}}$ construct, the singlestranded DNA templates including the $5^{\prime}$-T7 promotor sequence where chemically synthesized using DNA phosphoramidites (Thermo Fisher Scientific), cleaved from solid support and PCR amplified using DreamTaq DNA Polymerase (Thermo Fisher Scientific) according to the manufacturer's instructions. The T7 forward and methoxy reverse primer were used. To purify the dsDNA, we used Wizard spin columns (Promega). To increase the purity and quantity of the dsDNA PCR products, they were reamplified in a second PCR reaction with Phusion DNA Polymerase (Thermo Fisher Scientific) in $1 \times$ HF buffer to give dsDNA templates for R-99 wt $_{\text {and }}$ R- $99_{\mathrm{G}}$. Using dsDNA templates from above, RNA was in vitro transcribed using T7 RNA polymerase (Thermo Fisher Scientific) according to the manufacturer's instructions. The RNA was recovered using RNA Clean and Concentrator (Zymo Research) and analyzed on a $10 \%$ denaturing PAGE. To prepare the R-99 construct, a chemically synthesized 40 nt-long acceptor oligoribonucleotide encompassing the three inosine nucleosides was ligated with an in vitro transcribed 115 nt-long donor RNA. To this end, a ssDNA R-99 I donor template purchased (Microsynth) was amplified with Phusion DNA Polymer- 
ase (Thermo Fisher Scientific) in $1 \times$ HF buffer, 3\% DMSO. The T7 forward and methoxy reverse primer were used. To purify the PCR product, we used Wizard spin columns (Promega). From this dsDNA template, RNA was in vitro transcribed using T7 RNA polymerase (ThermoFisher Scientific) according to the manufacturer's instructions. The $5^{\prime}$-terminal triphosphate was converted into a $5^{\prime}$ monophosphate by using RNA $5^{\prime}$ pyrophosphohydrolase RppH (New England Biolabs). For this reaction, 315 pmol of RNA was converted into $5^{\prime}$-monophosphate in the presence of 30 units $\mathrm{RppH}$ enzyme for $1 \mathrm{~h}$ at $37^{\circ} \mathrm{C}$. The RNA was recovered with RNA Clean and Concentrator (Zymo Research). Then, 315 pmol donor 5'monophosphate RNA together with $2.9 \mathrm{nmol}$ acceptor RNA was heated for $5 \mathrm{~min}$ at $95{ }^{\circ} \mathrm{C}$ and slowly cooled to RT for $1 \mathrm{~h}$. Before, the ligation reaction was incubated for $1 \mathrm{~h}$ at $37^{\circ} \mathrm{C}$, T4 RNA ligase 2 buffer $(1 \times$ final concentration) and 10 units T4 RNA ligase 2 (New England Biolabs) were added. The ligation product was analyzed on a $10 \%$ denaturing PAGE and purified on a $10 \%$ preparative denaturing PAGE, visualized by UV shadowing, and the desired product was excised from the gel. After freezing in dry ice for $15 \mathrm{~min}$, the RNA was eluted from the gel piece in $20 \mathrm{mM}$ Tris- $\mathrm{HCl} \mathrm{pH} 7.5,0.25 \mathrm{M} \mathrm{NaOAc}$, $1 \mathrm{mM}$ EDTA, $0.25 \% \mathrm{SDS}$ at $4{ }^{\circ} \mathrm{C}$ overnight. The tube was centrifuged at maximum speed for $10 \mathrm{~min}$, and the RNA was recovered from the supernatant by ethanol precipitation. The quality of the purified RNA was assessed on a $10 \%$ denaturing PAGE.

RT Stop Assay. To 3 pmol RNA, $3 \mu \mathrm{L}$ of homemade reverse transcription buffer was added to give a final concentration of $4 \mathrm{mM}$ $\mathrm{MgCl}_{2}, 20 \mathrm{mM}$ Tris- $\mathrm{HCl} \mathrm{pH}$ 7.5, $5 \mathrm{mM}$ DTT, $0.5 \mathrm{mM}$ dNTPs, and $150 \mathrm{mM}$ of the corresponding salt $(\mathrm{KCl}$ or $\mathrm{LiCl})$. One $\mu \mathrm{L} 10 \mu \mathrm{M}$ 6FAM fluorescently labeled reverse primer (Thermo Fisher Scientific) was added, and the sample was heated to $95^{\circ} \mathrm{C}$ for $1.5 \mathrm{~min}$, chilled on ice for $1.5 \mathrm{~min}$, and equilibrated for $15 \mathrm{~min}$ at $37^{\circ} \mathrm{C}$. Subsequently 0.5 $\mu \mathrm{L}$ MultiScribe Reverse Transcriptase (Thermo Fisher Scientific) was added, and the RT reaction was incubated at $37^{\circ} \mathrm{C}$ for $50 \mathrm{~min}$. To degrade the template, RNA $0.5 \mu \mathrm{L} \mathrm{NaOH}(2 \mathrm{M})$ was added and heated up to $95{ }^{\circ} \mathrm{C}$ for $10 \mathrm{~min}$. To neutralize the sample, $0.5 \mu \mathrm{L} \mathrm{HCl}$ $(2 \mathrm{M})$ was added. The Thermo Sequenase Sequencing kit (Thermo Fisher Scientific) was used to produce sequencing ladders. For a 32 $\mu \mathrm{L}$ sequencing reaction, $16 \mu \mathrm{L}$ of the corresponding ddN termination mix, 0.5 pmol template DNA, $1.8 \mu \mathrm{L}$ reaction buffer, 10 pmol 6 FAM or PET fluorescently labeled reverse primer (Thermo Fisher Scientific), and $2 \mu \mathrm{L}$ sequenase were combined in a PCR tube. The cycling program was performed on a Thermocycler with 50 cycles at $95{ }^{\circ} \mathrm{C}$ for $30 \mathrm{~s}, 58{ }^{\circ} \mathrm{C}$ for $30 \mathrm{~s}$, and $72{ }^{\circ} \mathrm{C}$ for $90 \mathrm{~s}$. DNA from RT stop experiments and sequencing reactions was precipitated with 0.1 volume of $3 \mathrm{M} \mathrm{NaOAc}, 0.1$ volume of $100 \mathrm{mM}$ EDTA, 1.5 volume of ice-cold absolute EtOH, and $250 \mu \mathrm{g}$ glycogen at $-20{ }^{\circ} \mathrm{C}$ overnight. The sample was centrifuged at $4{ }^{\circ} \mathrm{C}$ at maximum speed, washed twice with ice-cold $75 \% \mathrm{EtOH}$, and dried in a SpeedVac for $10 \mathrm{~min}$. The DNA pellet was resuspended in $20 \mu \mathrm{L}$ Hi-Di formamide (Thermo Fisher Scientific) by heating up to $65{ }^{\circ} \mathrm{C}$ for $10 \mathrm{~min}$ and vortexing. Before being size fractioned on an $\mathrm{ABI} 3130 \mathrm{xl}$ sequencer, $1 \mu \mathrm{L} 500$ LIZ dye size standard (Thermo Fisher Scientific) was added, and the sample heated up to $95^{\circ} \mathrm{C}$ for $3 \mathrm{~min}$ and cooled on ice for $3 \mathrm{~min}$. The injection time was set to $5 \mathrm{~s}$. The data were analyzed using the Microsatellite plugin in Geneious.

Comparative Genomics. We performed alignment of the human HLA-B exon4/intron4 splice junction with the genomic coordinates $\mathrm{Chr} 6$, reverse strand, position 31,355,223-31,355,324, against 89 eutherian mammals. We identified 38 eutherian mammals with alignment in this region. The alignment was performed in the ensembl genome browser with the genomic assembly GRCh38.p13 (GCA_000001405.28) using the alignment tool (90 eutherian mammals EPO-Low-Coverage). A sequence logo of the reverse complement of this genomic sequence was generated using WebLogo 3.7.4. ${ }^{73}$ For a clearer presentation of the sequence logo, the insertion unique to Bonobo/Chimpanzee/Gorilla (5'-CTTCTGGAGCC-3') between bases 58 and 59 is not shown in Figure $3 \mathrm{~b}$.

Temperature-Controlled ESI-MS. The oligoribonucleotides were prepared at $30 \mu \mathrm{M}$ in $50 \mathrm{mM}$ trimethylammonium acetate buffer (TMAA; HPLC grade, Fluka), pH 7.4. To promote quadruplex formation, $\mathrm{KCl}$ (>99.999\%, Sigma-Aldrich) was added to a final concentration of $0.1 \mathrm{mM}$. Negative mode was used to record mass spectra (mass range $m / z 300-3500,1 \mathrm{~s}$ scanning rate) utilizing an ion-mobility spectrometer (IMS) hyphenated with a time-of-flight (TOF) MS (Synapt G2S, Waters). Cesium iodide (99.999\%, analytical standard for HR-MS, Fluka) in 50:50 acetonitrile:water was used as a calibration solution. The parameters of the TOF analyzer ("resolution mode") were: $0.9-1.5 \mathrm{kV}$ capillary voltage, $60 \mathrm{~V}$ sampling cone, $20-60 \mathrm{~V}$ source offset, $30^{\circ} \mathrm{C}$ source temperature, $4 \mathrm{~V}$ trap collision energy, $2 \mathrm{~V}$ transfer collision energy, and $3 \mathrm{~mL} / \mathrm{min}$ trap gas flow. A 6-bases long oligonucleotide $\mathrm{d}(\mathrm{T}) 6$ at $2.5 \mu \mathrm{M}$ was added, and intensities were normalized to this internal standard. A laboratory-built temperature-controlled nanoelectrospray (TCnESI) source first reported by Marchand et al. ${ }^{39}$ was used. In this setup, a borosilicate nanospray emitter (i.d. $\approx 1 \mu \mathrm{m}$ ) was made using a micropipette puller equipped with metal filament (P1000, Sutter Instrument) and filled with $5-10 \mu \mathrm{L}$ of the sample solution. The emitter was placed between two temperature-controlled (using Peltier element) copper blocks, guaranteeing a uniform temperature that can be varied between 15 and $90{ }^{\circ} \mathrm{C}$. The temperature increase rate was set to $2{ }^{\circ} \mathrm{C} / \mathrm{min}$. Signals of interest, related to the specific quadruplex form, were integrated $(2 \mathrm{~m} / z$ window), summed, normalized, and plotted as a function of temperature. Taken charge states were usually between $5^{-}$and $8^{-}$. Chemical noise subtraction was performed for each charge state individually.

Luciferase Reporter Assay. ZBTB2 reporter plasmid was generated by cloning synthesized target-site insert (Microsynth), into psiCHECK2 vector (cat. no. C8021, Promega). Target-site sequence used for the cloning was as follows: 5'-CCTCCA CTTCAGCCAGGACTCGAGTCACAAGACAAAACAGGAGCCAGAAGTAAGGACTGAAGGGCGGCCGCTGAGTCTTCGGACCTCGC-3'. $1.5 \times 10^{4}$ HEK293T cells (ATCC CRL-3216, Wesel, DE) were seeded in DMEM (Gibco, Invitrogen) supplemented with 10\% FBS (Gibco, Invitrogen) on 96-well plates. After 8 $\mathrm{h}$ following seeding, cells were transfected with RNA in technical triplicates, using Lipofectamine 2000 (cat. no. 11668019, Thermo Fisher Scientific) according to the manufacturer's protocol. RNA transfections were done with $0 \mathrm{nM}$ or $2.5 \mathrm{nM}$ of WT pre-miRNA149, MUT pre-miRNA149, G48-to-I variant of pre-miRNA149, G48-to-A variant of pre-miRNA149, positive control RNA (siRenilla acting against Renilla luciferase), and negative control RNA (doublestranded RNAs carrying randomized base pairs). ${ }^{74}$ Prior to transfection, RNAs were prefolded in $10 \mathrm{mM}$ Tris- $\mathrm{HCl}$ ( $\mathrm{pH} 7.5$ ), $100 \mathrm{mM}$ $\mathrm{KCl}$ by heating them for $5 \mathrm{~min}$ at $95{ }^{\circ} \mathrm{C}$ before equilibrating for 60 $\mathrm{min}$ at room temperature. After $24 \mathrm{~h}$ following RNA transfection, cells were transfected with $20 \mathrm{ng}$ /well of plasmid carrying ZBTB2 target site, using JetPEI (cat. no. 10110N, Polyplus Transfection) according to the manufacturer's protocol. After $48 \mathrm{~h}$ following the plasmid transfection, luciferase readout was conducted according to the manufacturer's protocol (Dual-Glo Luciferase Assay System, Promega) with $30 \mu \mathrm{L} /$ well Dual-Glo Luciferase Reagent diluted in 1:1 ratio with $\mathrm{H}_{2} \mathrm{O}$, and $15 \mu \mathrm{L} /$ well of Dual-Glo Stop \& Glo Reagent. Luminescence readout was performed on a microtiter plate reader (Mithras LB940, Berthold Technologies). Readout values were normalized to the Firefly luciferase counts and additionally to the corresponding values obtained from $0 \mathrm{nM}$ treatment.

Screening for Predicted GI-Quadruplex Forming Sequences. Prediction of PIQS was performed in R using the pqsfinder tool. ${ }^{53} 2,576,459$ A-to-I editing sites were obtained from the RADAR database. $^{52}$ The biomaRt package ${ }^{75}$ was used to obtain transcript sequences (genome assembly hg19). Custom R scripts were used to integrate edited sites into transcript sequences.

Pqsfinder ${ }^{53}$ was used with the following settings: Strand = "+", $\max$ len $=40 \mathrm{~L}$, min score $=10 \mathrm{~L}$, run re $=$ "[G,I] $\{1,10\}[\mathrm{G}, \mathrm{I}]\{0,9\}$ $[\mathrm{G}, \mathrm{I}]\{1,10\}$ ”, max_bulges $=3 \mathrm{~L}$, max_mismatches $=3 \mathrm{~L}$, max_defects $=3 \mathrm{~L}$, tetrad bonus $=40 \mathrm{~L}$, mismatch penalty $=0 \mathrm{~L}$, bulge penalty $=$ OL, bulge_len_factor $=0$, bulge_len_exponent $=0$, loop_min_len $=$ $1 \mathrm{~L}$. 
To filter the PIQS results further in Figure S9, we only allowed PIQS with $\geq 3$ quartets and at least one "HGIGH", "HGGIH", or "HIGGH" run, where $\mathrm{H}=\mathrm{A}, \mathrm{C}$, or $\mathrm{T}$.

\section{ASSOCIATED CONTENT}

\section{s) Supporting Information}

The Supporting Information is available free of charge at https://pubs.acs.org/doi/10.1021/jacs.1c05214.

Sequence information, CD, UV melting, ${ }^{1} \mathrm{H}$ NMR, and Dicer processing data, and bioinformatic prediction, including Figures S1-S11 and Tables S1 and S2 (PDF) List of predicted GI-quadruplexes (PIQS) in human UTRs (XLSX)

\section{AUTHOR INFORMATION}

\section{Corresponding Author}

Jonathan Hall - Department of Chemistry and Applied Biosciences, ETH Zurich, 8093 Zurich, Switzerland; (1) orcid.org/0000-0003-4160-7135; Email: Jonathan.hall@ pharma.ethz.ch

\section{Authors}

Timo Hagen - Department of Chemistry and Applied Biosciences, ETH Zurich, 8093 Zurich, Switzerland; (1) orcid.org/0000-0003-0139-6011

Artur Laski - Department of Chemistry and Applied Biosciences, ETH Zurich, 8093 Zurich, Switzerland; (1) orcid.org/0000-0001-6552-5367

Anneke Brümmer - Department of Computational Biology, University of Lausanne, 1015 Lausanne, Switzerland; Swiss Institute of Bioinformatics, 1015 Lausanne, Switzerland; (1) orcid.org/0000-0002-3576-0750

Adam Pruška - Department of Chemistry and Applied Biosciences, ETH Zurich, 8093 Zurich, Switzerland; (1) orcid.org/0000-0002-5304-2541

Verena Schlösser - Department of Chemistry and Applied Biosciences, ETH Zurich, 8093 Zurich, Switzerland; (1) orcid.org/0000-0001-5734-1234

Antoine Cléry - Department of Biology and Biomolecular NMR Spectroscopy Platform, ETH Zurich, 8093 Zurich, Switzerland

Frédéric H.-T. Allain - Department of Biology, ETH Zurich, 8093 Zurich, Switzerland

Renato Zenobi - Department of Chemistry and Applied Biosciences, ETH Zurich, 8093 Zurich, Switzerland; (1) orcid.org/0000-0001-5211-4358

Sven Bergmann - Department of Computational Biology, University of Lausanne, 1015 Lausanne, Switzerland; Swiss Institute of Bioinformatics, 1015 Lausanne, Switzerland; Department of Integrative Biomedical Sciences, University of Cape Town, 7925 Cape Town, South Africa

Complete contact information is available at: https://pubs.acs.org/10.1021/jacs.1c05214

\section{Notes}

The authors declare no competing financial interest.

\section{ACKNOWLEDGMENTS}

We thank Stefano Gallo and Boris Abramovic for the help with optimizing the RT stop assay and running native PAGE, respectively. RT stop data produced and analysed in this paper were generated in collaboration with the Genetic Diversity
Centre (GDC), ETH Zurich. Thanks to Prof. Mihaela Zavolan for feedback on the manuscript. Thanks to Anna Knörlein for the preparation of NMR samples. Thanks to Mauro Zimmermann and Anna Malinowska for the help with oligo synthesis. This work was supported by grants from the Swiss National Science Foundation: nos. FN 310030 152724/1 to S.B., 200020_178765 to R.Z., and the NCCR RNA and Disease of the SNSF to F.H.-T.A.

\section{REFERENCES}

(1) Yang, S. Y.; Lejault, P.; Chevrier, S.; Boidot, R.; Robertson, A. G.; Wong, J. M. Y.; Monchaud, D. Transcriptome-wide identification of transient RNA G-quadruplexes in human cells. Nat. Commun. 2018, 9 (1), 4730.

(2) Kwok, C. K.; Marsico, G.; Sahakyan, A. B.; Chambers, V. S.; Balasubramanian, S. rG4-seq reveals widespread formation of Gquadruplex structures in the human transcriptome. Nat. Methods 2016, 13 (10), 841-4.

(3) Millevoi, S.; Moine, H.; Vagner, S. G-quadruplexes in RNA biology. Wires Rna 2012, 3 (4), 495-507.

(4) Fay, M. M.; Lyons, S. M.; Ivanov, P. RNA G-Quadruplexes in Biology: Principles and Molecular Mechanisms. J. Mol. Biol. 2017, 429 (14), 2127-2147.

(5) Varshney, D.; Spiegel, J.; Zyner, K.; Tannahill, D.; Balasubramanian, S. The regulation and functions of DNA and RNA G-quadruplexes. Nat. Rev. Mol. Cell Biol. 2020, 21 (8), 459474.

(6) Bhattacharyya, D.; Mirihana Arachchilage, G.; Basu, S. Metal Cations in G-Quadruplex Folding and Stability. Front. Chem. 2016, 4, 38.

(7) Pandey, S.; Agarwala, P.; Maiti, S. Effect of loops and G-quartets on the stability of RNA G-quadruplexes. J. Phys. Chem. B 2013, 117 (23), 6896-6905.

(8) Lightfoot, H. L.; Hagen, T.; Tatum, N. J.; Hall, J. The diverse structural landscape of quadruplexes. FEBS Lett. 2019, 593 (16), 2083-2102.

(9) Huang, H.; Suslov, N. B.; Li, N. S.; Shelke, S. A.; Evans, M. E.; Koldobskaya, Y.; Rice, P. A.; Piccirilli, J. A. A G-quadruplexcontaining RNA activates fluorescence in a GFP-like fluorophore. Nat. Chem. Biol. 2014, 10 (8), 686-91.

(10) Phan, A. T.; Kuryavyi, V.; Darnell, J. C.; Serganov, A.; Majumdar, A.; Ilin, S.; Raslin, T.; Polonskaia, A.; Chen, C.; Clain, D.; Darnell, R. B.; Patel, D. J. Structure-function studies of FMRP RGG peptide recognition of an RNA duplex-quadruplex junction. Nat. Struct. Mol. Biol. 2011, 18 (7), 796-804.

(11) Dethoff, E. A.; Chugh, J.; Mustoe, A. M.; Al-Hashimi, H. M. Functional complexity and regulation through RNA dynamics. Nature 2012, 482 (7385), 322-330.

(12) Bass, B. L.; Weintraub, H. A developmentally regulated activity that unwinds RNA duplexes. Cell 1987, 48 (4), 607-13.

(13) Wagner, R. W.; Smith, J. E.; Cooperman, B. S.; Nishikura, K. A double-stranded RNA unwinding activity introduces structural alterations by means of adenosine to inosine conversions in mammalian cells and Xenopus eggs. Proc. Natl. Acad. Sci. U. S. A. 1989, 86 (8), 2647-51.

(14) Nishikura, K. A-to-I editing of coding and non-coding RNAs by ADARs. Nat. Rev. Mol. Cell Biol. 2016, 17 (2), 83-96.

(15) Kawahara, Y.; Zinshteyn, B.; Sethupathy, P.; Iizasa, H.; Hatzigeorgiou, A. G.; Nishikura, K. Redirection of silencing targets by adenosine-to-inosine editing of miRNAs. Science 2007, 315 (5815), 1137-40.

(16) Yang, W.; Chendrimada, T. P.; Wang, Q.; Higuchi, M.; Seeburg, P. H.; Shiekhattar, R.; Nishikura, K. Modulation of microRNA processing and expression through RNA editing by ADAR deaminases. Nat. Struct. Mol. Biol. 2006, 13 (1), 13-21.

(17) Brummer, A.; Yang, Y.; Chan, T. W.; Xiao, X. Structuremediated modulation of mRNA abundance by A-to-I editing. Nat. Commun. 2017, 8 (1), 1255. 
(18) Solomon, O.; Di Segni, A.; Cesarkas, K.; Porath, H. T.; MarcuMalina, V.; Mizrahi, O.; Stern-Ginossar, N.; Kol, N.; Farage-Barhom, S.; Glick-Saar, E.; Lerenthal, Y.; Levanon, E. Y.; Amariglio, N.; Unger, R.; Goldstein, I.; Eyal, E.; Rechavi, G. RNA editing by ADAR1 leads to context-dependent transcriptome-wide changes in RNA secondary structure. Nat. Commun. 2017, 8 (1), 1440.

(19) Belkadi, A.; Thareja, G.; Halama, A.; Mahmoud, Y.; Jones, D.; Agnew, S.; Malek, J.; Suhre, K. Identification of genetic variants controlling RNA editing and their effect on RNA structure stabilization. Eur. J. Hum. Genet. 2020, 28 (12), 1753-1762.

(20) Liddicoat, B. J.; Piskol, R.; Chalk, A. M.; Ramaswami, G.; Higuchi, M.; Hartner, J. C.; Li, J. B.; Seeburg, P. H.; Walkley, C. R. RNA editing by ADAR1 prevents MDA5 sensing of endogenous dsRNA as nonself. Science 2015, 349 (6252), 1115-20.

(21) Tan, M. H.; Li, Q.; Shanmugam, R.; Piskol, R.; Kohler, J.; Young, A. N.; Liu, K. I.; Zhang, R.; Ramaswami, G.; Ariyoshi, K.; Gupte, A.; Keegan, L. P.; George, C. X.; Ramu, A.; Huang, N.; Pollina, E. A.; Leeman, D. S.; Rustighi, A.; Goh, Y. P. S.; Chawla, A.; Del Sal, G.; Peltz, G.; Brunet, A.; Conrad, D. F.; Samuel, C. E.; O'Connell, M. A.; Walkley, C. R.; Nishikura, K.; Li, J. B. Dynamic landscape and regulation of RNA editing in mammals. Nature 2017, 550 (7675), 249-254.

(22) Wahlstedt, H.; Daniel, C.; Enstero, M.; Ohman, M. Large-scale mRNA sequencing determines global regulation of RNA editing during brain development. Genome Res. 2009, 19 (6), 978-86.

(23) Porath, H. T.; Carmi, S.; Levanon, E. Y. A genome-wide map of hyper-edited RNA reveals numerous new sites. Nat. Commun. 2014, 5,4726 .

(24) Risitano, A.; Fox, K. R. Inosine substitutions demonstrate that intramolecular DNA quadruplexes adopt different conformations in the presence of sodium and potassium. Bioorg. Med. Chem. Lett. 2005, 15 (8), 2047-50.

(25) Jara-Espejo, M.; Fleming, A. M.; Burrows, C. J. Potential GQuadruplex Forming Sequences and N(6)-Methyladenosine Colocalize at Human Pre-mRNA Intron Splice Sites. ACS Chem. Biol. 2020, 15 (6), 1292-1300.

(26) Pandolfini, L.; Barbieri, I.; Bannister, A. J.; Hendrick, A.; Andrews, B.; Webster, N.; Murat, P.; Mach, P.; Brandi, R.; Robson, S. C.; Migliori, V.; Alendar, A.; d'Onofrio, M.; Balasubramanian, S.; Kouzarides, T. METTL1 Promotes let-7 MicroRNA Processing via m7G Methylation. Mol. Cell 2019, 74 (6), 1278-1290.

(27) Hagen, T.; Malinowska, A. L.; Lightfoot, H. L.; Bigatti, M.; Hall, J. Site-Specific Fluorophore Labeling of Guanosines in RNA GQuadruplexes. ACS Omega 2019, 4 (5), 8472-8479.

(28) Mergny, J. L.; Lacroix, L. UV Melting of G-Quadruplexes. Curr. Protoc Nucleic Acid Chem. 2009, 37, 17.1.1-17.1.15.

(29) Weldon, C.; Behm-Ansmant, I.; Hurley, L. H.; Burley, G. A.; Branlant, C.; Eperon, I. C.; Dominguez, C. Identification of Gquadruplexes in long functional RNAs using 7-deazaguanine RNA. Nat. Chem. Biol. 2017, 13 (1), 18-20.

(30) Murchie, A. I.; Lilley, D. M. Retinoblastoma susceptibility genes contain $5^{\prime}$ sequences with a high propensity to form guanine-tetrad structures. Nucleic Acids Res. 1992, 20 (1), 49-53.

(31) Bugaut, A.; Rodriguez, R.; Kumari, S.; Hsu, S. T. D.; Balasubramanian, S. Small molecule-mediated inhibition of translation by targeting a native RNA G-quadruplex. Org. Biomol. Chem. 2010, 8 (12), 2771-2776.

(32) Nishikura, K.; Yoo, C.; Kim, U.; Murray, J. M.; Estes, P. A.; Cash, F. E.; Liebhaber, S. A. Substrate specificity of the dsRNA unwinding/modifying activity. EMBO J. 1991, 10 (11), 3523-32.

(33) Harkness, R. W.; Mittermaier, A. K. G-register exchange dynamics in guanine quadruplexes. Nucleic Acids Res. 2016, 44 (8), $3481-3494$.

(34) Adrian, M.; Heddi, B.; Phan, A. T. NMR spectroscopy of Gquadruplexes. Methods 2012, 57 (1), 11-24.

(35) Vorlickova, M.; Kejnovska, I.; Sagi, J.; Renciuk, D.; Bednarova, K.; Motlova, J.; Kypr, J. Circular dichroism and guanine quadruplexes. Methods 2012, 57 (1), 64-75.
(36) Guiset Miserachs, H.; Donghi, D.; Börner, R.; Johannsen, S.; Sigel, R. K. O. Distinct differences in metal ion specificity of RNA and DNA G-quadruplexes. JBIC, J. Biol. Inorg. Chem. 2016, 21 (8), 975986

(37) Thier, S. O. Potassium physiology. Am. J. Med. 1986, 80 (4A), $3-7$.

(38) Maltby, C. J.; Schofield, J. P. R.; Houghton, S. D.; O’Kelly, I.; Vargas-Caballero, M.; Deinhardt, K.; Coldwell, M. J. A 5' UTR GGN repeat controls localisation and translation of a potassium leak channel mRNA through G-quadruplex formation. Nucleic Acids Res. 2020, 48 (17), 9822-9839.

(39) Marchand, A.; Rosu, F.; Zenobi, R.; Gabelica, V. Thermal Denaturation of DNA G-Quadruplexes and Their Complexes with Ligands: Thermodynamic Analysis of the Multiple States Revealed by Mass Spectrometry. J. Am. Chem. Soc. 2018, 140 (39), 12553-12565.

(40) Pruska, A.; Marchand, A.; Zenobi, R. Novel Insight into Proximal DNA Domain Interactions from Temperature-Controlled Electrospray Ionization Mass Spectrometry. Angew. Chem., Int. Ed. 2021, 60 (28), 15390-15398.

(41) Smith, F. W.; Feigon, J. Quadruplex structure of Oxytricha telomeric DNA oligonucleotides. Nature 1992, 356 (6365), 164-168.

(42) Bugaut, A.; Murat, P.; Balasubramanian, S. An RNA hairpin to g-quadruplex conformational transition. J. Am. Chem. Soc. 2012, 134 (49), 19953-19956.

(43) Paige, J. S.; Wu, K. Y.; Jaffrey, S. R. RNA mimics of green fluorescent protein. Science 2011, 333 (6042), 642-6.

(44) Strack, R. L.; Disney, M. D.; Jaffrey, S. R. A superfolding Spinach2 reveals the dynamic nature of trinucleotide repeatcontaining RNA. Nat. Methods 2013, 10 (12), 1219-24.

(45) Mullen, M. A.; Assmann, S. M.; Bevilacqua, P. C. Toward a digital gene response: RNA G-quadruplexes with fewer quartets fold with higher cooperativity. J. Am. Chem. Soc. 2012, 134 (2), 812-815.

(46) Guo, J. U.; Bartel, D. P. RNA G-quadruplexes are globally unfolded in eukaryotic cells and depleted in bacteria. Science 2016, 353 (6306), aaf5371.

(47) Kwok, C. K.; Balasubramanian, S. Targeted Detection of GQuadruplexes in Cellular RNAs. Angew. Chem., Int. Ed. 2015, 54 (23), 6751-4.

(48) Zuker, M. Mfold web server for nucleic acid folding and hybridization prediction. Nucleic Acids Res. 2003, 31 (13), 3406-15.

(49) Kharel, P.; Becker, G.; Tsvetkov, V.; Ivanov, P. Properties and biological impact of RNA G-quadruplexes: from order to turmoil and back. Nucleic Acids Res. 2020, 48 (22), 12534-12555.

(50) Gomez, D.; Lamarteleur, T.; Lacroix, L.; Mailliet, P.; Mergny, J. L.; Riou, J. F. Telomerase downregulation induced by the Gquadruplex ligand 12459 in A549 cells is mediated by hTERT RNA alternative splicing. Nucleic Acids Res. 2004, 32 (1), 371-379.

(51) Didiot, M. C.; Tian, Z.; Schaeffer, C.; Subramanian, M.; Mandel, J. L.; Moine, H. The G-quartet containing FMRP binding site in FMR1 mRNA is a potent exonic splicing enhancer. Nucleic Acids Res. 2008, 36 (15), 4902-12.

(52) Ramaswami, G.; Li, J. B. RADAR: a rigorously annotated database of A-to-I RNA editing. Nucleic Acids Res. 2014, 42, D109D113.

(53) Hon, J.; Martinek, T.; Zendulka, J.; Lexa, M. pqsfinder: an exhaustive and imperfection-tolerant search tool for potential quadruplex-forming sequences in R. Bioinformatics 2017, 33 (21), 3373-3379.

(54) Lee, D. S. M.; Ghanem, L. R.; Barash, Y. Integrative analysis reveals RNA G-quadruplexes in UTRs are selectively constrained and enriched for functional associations. Nat. Commun. 2020, 11 (1), 527.

(55) Ghosh, A.; Ekka, M. K.; Tawani, A.; Kumar, A.; Chakraborty, D.; Maiti, S. Restoration of miRNA-149 Expression by TmPyP4 Induced Unfolding of Quadruplex within Its Precursor. Biochemistry 2019, 58 (6), 514-525.

(56) Kwok, C. K.; Sahakyan, A. B.; Balasubramanian, S. Structural Analysis using SHALiPE to Reveal RNA G-Quadruplex Formation in Human Precursor MicroRNA. Angew. Chem., Int. Ed. 2016, 55 (31), $8958-8961$. 
(57) Bartel, D. P. Metazoan MicroRNAs. Cell 2018, 173 (1), $20-51$.

(58) Wang, Y.; Zheng, X.; Zhang, Z.; Zhou, J.; Zhao, G.; Yang, J.; Xia, L.; Wang, R.; Cai, X.; Hu, H.; Zhu, C.; Nie, Y.; Wu, K.; Zhang, D.; Fan, D. MicroRNA-149 inhibits proliferation and cell cycle progression through the targeting of ZBTB2 in human gastric cancer. PLoS One 2012, 7 (10), e41693.

(59) Mirihana Arachchilage, G.; Dassanayake, A. C.; Basu, S. A potassium ion-dependent RNA structural switch regulates human premiRNA 92b maturation. Chem. Biol. 2015, 22 (2), 262-72.

(60) Wan, Y.; Kertesz, M.; Spitale, R. C.; Segal, E.; Chang, H. Y. Understanding the transcriptome through RNA structure. Nat. Rev. Genet. 2011, 12 (9), 641-655.

(61) Ganser, L. R.; Kelly, M. L.; Herschlag, D.; Al-Hashimi, H. M. The roles of structural dynamics in the cellular functions of RNAs. Nat. Rev. Mol. Cell Biol. 2019, 20 (8), 474-489.

(62) Lightfoot, H. L.; Hagen, T.; Clery, A.; Allain, F. H.; Hall, J. Control of the polyamine biosynthesis pathway by G2-quadruplexes. eLife 2018, 7, e36362.

(63) Liu, N.; Dai, Q.; Zheng, G.; He, C.; Parisien, M.; Pan, T. N(6)methyladenosine-dependent RNA structural switches regulate RNAprotein interactions. Nature 2015, 518 (7540), 560-4.

(64) Curtis, E. A.; Liu, D. R. Discovery of widespread GTP-binding motifs in genomic DNA and RNA. Chem. Biol. 2013, 20 (4), 521-32.

(65) Lane, A. N.; Chaires, J. B.; Gray, R. D.; Trent, J. O. Stability and kinetics of G-quadruplex structures. Nucleic Acids Res. 2008, 36 (17), 5482-515.

(66) Sauer, M.; Juranek, S. A.; Marks, J.; De Magis, A.; Kazemier, H. G.; Hilbig, D.; Benhalevy, D.; Wang, X.; Hafner, M.; Paeschke, K. DHX36 prevents the accumulation of translationally inactive mRNAs with G4-structures in untranslated regions. Nat. Commun. 2019, 10 (1), 2421.

(67) von Hacht, A.; Seifert, O.; Menger, M.; Schutze, T.; Arora, A.; Konthur, Z.; Neubauer, P.; Wagner, A.; Weise, C.; Kurreck, J. Identification and characterization of RNA guanine-quadruplex binding proteins. Nucleic Acids Res. 2014, 42 (10), 6630-44.

(68) Endoh, T.; Sugimoto, N. Conformational Dynamics of the RNA G-Quadruplex and its Effect on Translation Efficiency. Molecules 2019, 24 (8), 1613.

(69) Pandey, S.; Agarwala, P.; Jayaraj, G. G.; Gargallo, R.; Maiti, S. The RNA Stem-Loop to G-Quadruplex Equilibrium Controls Mature MicroRNA Production inside the Cell. Biochemistry 2015, 54 (48), 7067-78.

(70) Bass, B. L.; Weintraub, H. An unwinding activity that covalently modifies its double-stranded RNA substrate. Cell 1988, 55 (6), 108998.

(71) Schlosser, V.; Hall, J. Labeling microRNA precursors for Dicer assays. Anal. Biochem. 2019, 579, 35-37.

(72) Wilkinson, K. A.; Merino, E. J.; Weeks, K. M. Selective 2'hydroxyl acylation analyzed by primer extension (SHAPE): quantitative RNA structure analysis at single nucleotide resolution. Nat. Protoc. 2006, 1 (3), 1610-6.

(73) Crooks, G. E.; Hon, G.; Chandonia, J. M.; Brenner, S. E. WebLogo: a sequence logo generator. Genome Res. 2004, 14 (6), 1188-90.

(74) Zagalak, J. A.; Menzi, M.; Schmich, F.; Jahns, H.; Dogar, A. M.; Wullschleger, F.; Towbin, H.; Hall, J. Properties of short doublestranded RNAs carrying randomized base pairs: toward better controls for RNAi experiments. RNA 2015, 21 (12), 2132-42.

(75) Durinck, S.; Spellman, P. T.; Birney, E.; Huber, W. Mapping identifiers for the integration of genomic datasets with the $\mathrm{R}$ / Bioconductor package biomaRt. Nat. Protoc. 2009, 4 (8), 1184-91. 